\title{
Behavioral Strategies in Repeated Pure Coordination Games
}

\author{
Rami Zwick \\ Amnon Rapoport \\ Alison King Chung Lo
}

Series No. MKTG 00.152

November 27, 2000 


\title{
Behavioral Strategies in Repeated Pure Coordination Games
}

\author{
Rami Zwick \\ Hong Kong University of Science \\ and Technology \\ Amnon Rapoport \\ University of Arizona \\ Alison King C'hung Lo \\ Duke University
}

October 5, 2000

Please address all correspondence to:

Rami Zwick

Department of Marketing

Hong Kong University of Science and Technology

Clear water Bay, Kowloon,

Hong Kong

E-mail Address: mkzwick@ust.hk 


\begin{abstract}
We study experimentally a class of pure coordination games as a special case of the Consumer Choice of Prizes game developed by Rapoport et al. (2000). We find a high level of group coordination coupled with considerable switching in the choice of locations. Two models are proposed and tested to account for the results, one postulating the formation of conventions, and the other invoking the mixed strategy equilibrium solution for risk-neutral players. We reject both models as possible candidates to describe the behavioral regularities that we observe in the data. A third model that allows individual perturbations of commonly shared choice probabilities is proposed and tested. It accounts for the major results on the individual and aggregate levels.
\end{abstract}




\section{Introduction}

Consider the case where demand for some indivisible good exceeds the supply. In accordance with market forces prices typically go up and thereby decrease the excess demand. However, in some cases, because of either government regulation, custom, or social pressures applied by consumer groups, prices remain fixed. To meet the excess demand, alternative mechanisms have been devised to allocate the limited supply among the claimants. A commonly used mechanism allocates the goods according to the celebrated "first come, first served" principle. Seats in popular restaurants (where no reservations are taken) and newly introduced fashionable products (e.g., toys, records) are typically allocated in this manner. Although an argument can be made that this principle treats the claimants fairly, it has many disadvantages including, but not limited to, inefficient allocation of the good.

A second common mechanism is the priority list in which claimants are ranked according to some measure of need, contribution, power, or seniority. For example, kidneys in the US are allocated by criteria that are based on blood type, histologic match, and waiting time. These criteria are meant to be a compromise between delay of the surgery and graft success (histologic match). The problem with such mechanisms is that they cause endless debates about criteria of fairness that should underlie the construction of priority lists in different contexts. For example, who should get priority by the Hong Kong government while allocating the limited supply of housing, families seeking apartments or commercial investors seeking assets to resell? The criteria for determining priority lists must be socially accepted for the process to be perceived as fair.

A third mechanism, which is the focus of the present study, allocates the indivisible goods (hereafter referred to as "prizes") by lottery. For example, positions in some medical schools (Young, 1994), apartments in new development housing projects in Hong Kong, and prizes in state 
lotteries are allocated in this fashion. The principle underlying this mechanism, not shared by the former two mechanisms, is of no preferential treatment. Each claimant is assigned the same probability of receiving a prize regardless of time of arrival or assignment of priority. A major feature of the lottery mechanism is that the probability of receiving a prize is determined endogenously: the larger the number of claimants participating in the lottery, the smaller the probability that any one of them will receive one of the prizes.

Although determined endogenously, the probability of winning a prize is the outcome of some random device the properties of which are fully understood and commonly known. Rapoport, Lo, and Zwick (2000) noted that the lottery mechanism may also apply when the probability of winning a prize is subjective and commonly shared by all the players. For example, consider the case of $\mathbf{n}$ competing firms faced with a decision whether to enter a newly emerging market. Although no physical lotteries are involved in this case, each firm's decision is based on the probability it assigns to the event of successful entry which, in turn, depends on the number of entrants. If each firm estimates its probability of successful entry to be proportional to the number of entrants, then these commonly shared beliefs behave like a lottery.

Consider next the case where the demand for several independent indivisible goods exceeds the supply. If the principle of no preferential treatment is to be applied to this case, this situation can be modeled by several independent lotteries with endogenously determined probabilities, each offering a possibly different number of prizes at possibly different values. For example, households in Hong Kong seeking to relocate to public housing in one of the three non-urban areas (a commodity in short supply) can submit, if qualified, an application for re-housing (at a fixed rent). After the deadline, flats are allocated to the applicants by a lottery. Similarly, if they believe that their probability of being admitted to a certain program is proportional to the number of 
applicants for the same program, students applying for graduate studies are basically faced with multiple lotteries, each offering a different number of scholarships (prizes) at different values (e.g., prestige of the program, size of the scholarship). If the claimants can register to only one of the multiple lotteries because of regulation (as is the case in Hong Kong) or high application fees (as is sometimes the case in the graduate studies application example), the problem they face when trying to maximize their expected value is one of tacit coordination.

The study of tacit coordination under multiple lotteries with endogenously determined probabilities is part of a more general analysis of contingent behavior, which explores the relation between the behavior characteristics of the individuals who comprise some social aggregate and the characteristics of the aggregate (Schelling, 1978). The objectives of the members of the aggregate relate directly to other members, and these objectives are constrained by an environment that consists of other people who achieve their own objectives. Schelling pointed out that what makes the analysis interesting and difficult is that the entire aggregate outcome has to be evaluated, not merely how each member of the aggregate does within the constraints of his or her environment. As noted by many authors, an essential part of this analysis is empirical. To study coordination in the presence of multiple and independent lotteries under the constraint (which may be relaxed) of a single entry ${ }^{1}$ Rapoport et al. (2000) devised a non-cooperative nperson game, called the Consumers Choice of Prizes (CCP) game. This game was proposed to simulate the basic features of the tacit coordination problem when independent lotteries with endogenously determined probabilities are used simultaneously to allocate multiple goods (prizes), or the system of commonly shared beliefs behaves like a lottery.

1 One may impose differential costs of entry for the different lotteries or different players. If the costs are relatively high in comparison to the prizes offered by the lotteries, then they may constrain the participants from entering all the 
The rest of this paper is organized as follows. Section 2 presents the CCP game and constructs its Nash equilibria. Section 3 first presents the experimental design for a special case of the CCP game in which the prizes offered by the different lotteries are all equal, and then summarizes the results. Section 4 tests and subsequently rejects two alternative models proposed to account for the behavioral regularities observed in the data. It then proposes a third model with perturbed choice probabilities that accounts for the major individual and aggregate findings. Section 5 concludes.

\section{The CCP Game}

The CCP game is a non-cooperative n-person game with complete information. Formally, it presents to each of $n$ symmetric players $J$ alternatives (called locations) with $m_{j}$ identical prizes in each location $j(j=1,2, \ldots, J)$. Each prize is worth $g_{j}$ units. The values of $n, J, m_{j}$, and $g_{j}$ are commonly known.

Each player $i(i=1,2, \ldots, n)$ must decide independently and anonymously which location to enter. Thus, the strategy set of each player includes J elements. Denote the number of entrants in location $\mathrm{j}$ by $n_{j}\left(\sum_{j=1}^{j} n_{j}=n\right)$. Once all the n players make their entry decisions, individual payoffs are determined for each player as follows:

If $n_{j} \leq m_{j}$, each player entering location $j$ receives the prize $g_{j}$.

If $n_{j}>m_{j}$, exactly each of the $m_{j}$ (out of the $n_{j}$ ) entrants receives a prize of $g_{j}$. The remaining $n_{j}-$ $m_{j}$ entrants receive nothing. Every subset $m_{j} \subset n_{j}$ is equally likely to be selected. The CCP game imposes no cost of entry.

Pure Strategy Equilibria. There are $n ! /\left(n_{1}{ }^{*} ! n_{2}{ }^{*} ! \ldots n_{\mathrm{J}}{ }^{*} !\right)$ pure strategy equilibria consisting of $n_{1}{ }^{*}$,

lotteries. 
$\mathrm{n}_{2}^{*}, \ldots, \mathrm{n}_{\mathrm{J}}^{*}$ players entering locations $1,2, \ldots, \mathrm{J}$, respectively $\left(\sum_{j=1}^{J} \mathrm{n}_{\mathrm{j}}^{*}=\mathrm{n}\right)$, such that no single player benefits from unilaterally switching from location $j$ to location $j(j \neq j)$. Given the multiplicity of equilibria, the subjects are faced with a coordination problem.

Mixed Strategy Equilibria. In the symmetric mixed strategy equilibrium each of the $\mathrm{n}$ players enters locations $1,2, \ldots, J$ with respective probabilities $q_{1}, q_{2}, \ldots, q_{J}$. In equilibrium, the expected value associated with entering each of the $\mathrm{J}$ locations, denoted by $\mathrm{V}$, is the same. The equilibrium solution for risk-neutral players consists of the probabilities $q_{1}, q_{2}, \ldots, q_{J}$, that satisfy the following $J+1$ equations in $J+1$ unknown $\left(q_{1}, q_{2}, \ldots, q_{J}, V\right)$ :

$\mathrm{g}_{\mathrm{j}} \sum_{k=0}^{m_{j}-1}\left(\begin{array}{c}n-1 \\ k\end{array}\right) \mathrm{q}_{j}{ }^{\mathrm{k}}\left(1-\mathrm{q}_{\mathrm{j}}\right)^{\mathrm{n}-1-\mathrm{k}}+\mathrm{g}_{\mathrm{j}} \sum_{k=m}^{n-1}\left(\begin{array}{c}n-1 \\ k\end{array}\right)\left(\frac{m_{j}}{k+1}\right) \mathrm{q}_{\mathrm{j}}^{\mathrm{k}}\left(1-\mathrm{q}_{\mathrm{j}}\right)^{\mathrm{n}-1-\mathrm{k}}=\mathrm{V}$,

and

$\sum_{j=1}^{j} q_{j}=1, q_{j}>0, \quad \mathrm{j}=1,2, \ldots, \mathrm{J}$

In the general case, these equations are solved numerically.

The Pure Coordination Game. The present study examines a special case of the $\mathrm{CCP}$ game where $\mathrm{J}=3$, the number of prizes differs from one lottery to another, but the prize values are equal, i.e.. $\mathrm{g}_{\mathrm{j}}$ $\equiv \mathrm{g} \forall \mathrm{j}$. Moreover, we impose the restriction $\mathrm{m}_{1}+\mathrm{m}_{2}+\mathrm{m}_{3}=\mathrm{n}$. The pure strategy equilibrium is simply $n_{j}{ }^{*}=m_{j} \forall j$. The game presents the following task to the group of $n$ people: partition the group into $J$ subgroups of $m_{j}$ members each. If the task is successfully accomplished, and since $m_{1}$ $+m_{2}+\ldots+m_{J}=n$ by construction, the outcome uncertainty is eliminated and each player is assured a prize of equal value. Note that in equilibrium subjects are indifferent to which subgroup they belong, hence a no-conflict pure coordination task is at hand. This, of course, might have significant implications to the dynamics of repeated play of the same game. Subjects may 
understand what is required of them to achieve successful coordination in this case, a fact that could facilitate their ability to tacitly coordinate expectations and behavior.

\section{The Experiment}

\section{Method}

Subjects. Thirty-six subjects participated in two groups of eighteen subjects each. The subjects were Hong Kong University of Science and Technology students, mostly undergraduate students of Business Administration, who volunteered to take part in a single session of a decision making experiment with payoff contingent on performance. On the average, the subjects earned HK\$172.56 (US\$22.3) for their participation plus a HK\$30.00 (US\$3.9) show-up fee.

Design. The design consisted of six different games (Table 1) each of which iterated 16 times (blocks) for a total of 96 trials. The six games were constructed to span the way by which a group of 18 players can subdivide itself into three subgroups of almost equal number of members (Game 1), two small subgroups and one large (Game 6), and one small and two medium size subgroups (Game 4). The sum of the numbers of prizes was fixed at 18 for each game. Under pure strategy equilibrium play, the payoff per subject is $\$ 2.00$ per trial for a total of HK $\$ 192.00$ for the entire experiment.

Procedure. Upon arriving at the computer laboratory (which contains about $80 \mathrm{PCs}$ ), the subjects in each group were seated at eighteen computer terminals. These terminals were spread across the laboratory classroom. Communication between the subjects was strictly forbidden. The instructions were presented on the individual screens using PowerPoint slide show. The subjects read the instructions at their own pace with no time pressure. The text version of the instructions is presented in Appendix 1.

The subjects were instructed that they would participate in a series of games played repeatedly 
with the same group of eighteen subjects. Their task was to choose one of three lotteries, called (and marked on the screen) Yellow, Blue, and Red. At the beginning of each trial, the prize value (g) and number of prizes in each lottery $\left(\mathrm{m}_{\mathrm{j}}\right)$ were displayed to the subjects, who were then required to choose one of the three lotteries. Appendix 2 presents screen shots for the decision task. The subjects were instructed that the game parameters would vary from trial to trial. Once all of them made their decision, the three values of $n_{j}$ were displayed on the individual screens and the prizes were distributed.

After reading the information displayed on the first twelve screens, the subject's understanding of the procedure was tested through four hypothetical questions that varied the parameter values and number of entrants. The experiment commenced after all the subjects answered these questions correctly. The subjects were told that they would be paid their cumulative earnings at the end of the session plus a show-up fee.

Trials were arranged in 16 blocks of 6 trials each. In each block, Games 1 through 6 (Table 1) were presented in a possibly different random order. On the average, six trials separated two consecutive presentations (iterations) of the same game. To prevent response bias (e.g., color preference), the number of prizes for the same game was varied across colors in a balanced design. The entire experiment lasted about 75 minutes.

$$
\text { --Insert Table } 1 \text { about here- }
$$

\section{$\underline{\text { Results }}$}

Individual Results. Tables $2 \mathrm{~A}$ and $2 \mathrm{~B}$ present the individual data from this study ${ }^{2}$. Each $18 \times 16$ row (subject) by column (iteration) matrix presents the raw data from one of the six games. Each

2 The only non-reproducible information from these tables is the order by which the different 6 games were presented within each of the 16 blocks and the colors representing each location. 
cell in the matrix presents the (row) subject's choice in the (column's) replication (1 to 16). Black cells indicate a choice of $j=1$, gray cells a choice of $j=2$, and white cells a choice of $j=3$. A cell with a dot on top of it indicates that the subject was not rewarded on the column's replication. Cells without dots indicate that a reward was given. The top row above each game matrix presents a coordination index that will be explained later.

Tables $2 \mathrm{~A}$ and $2 \mathrm{~B}$ can assist in identifying individual patterns of behavior and general trends. For example, cells with dots on top of them are rather sparse, indicating that not being rewarded was the exception rather than the rule. Out of a total of $192(96 \times 2)$ trials across the two groups, we observe 21 cases in which all 18 subjects received the prize--6 in Group 1 (Table 2A) and 15 in Group 2 (Table 2B). These cases are marked with " 0 " at the top of the column. More than half of these cases occurred in Game 6. Across both groups. we find 6, 5, 5, 9, 6, and 18 subjects in Games $1,2,3,4,5$, and 6 , respectively, who received the prize on all 16 iterations of the game. Various subjects demonstrated consistent patterns of behavior. For example, subject 13 of Group 2 chose $\mathrm{j}=1$ on 95 of the 96 trials. Other subjects who almost always chose $\mathrm{j}=1$ on Games $3,4,5$, and 6 are subjects 2, 3, and 7 of Group 1 and subjects 4, 7 and 12 of Group 2. Other subjects chose the same location almost always in one game but not in others (e.g., subject 12 of Group 1 in Game 6), and yet others varied their choices across replications. Table 3 presents the games in which a subject chose the same location on at least 14 of the 16 replications. These games are indicated by a circle if the persistent behavior was choosing $\mathrm{j}=1$, a diamond for $\mathrm{j}=2$, and a square for $j=3$. As may be expected, most of the subjects ( 27 out of 36 ) chose location $j=1$ on Game 6 at least 14 times. Taken together, Tables $2 \mathrm{~A}, 2 \mathrm{~B}$, and 3 show a very heterogenous pattern of the subjects' behavior between games and across iterations of the same game. Yet, as we show below, a high level of coordination was achieved in all games. 
-- Insert Tables 2A 2B, and 3 bout here --

Aggregate Behavior. In studying aggregate behavior, the major dependent variable is the level of group coordination. We evaluate it by a proximity measure between observed and predicted (pure strategy equilibrium) number of entrants in each location. The proximity measure is simply the minimum number of subjects who have to switch their choices, given some distribution of choices, to achieve pure strategy equilibrium. For example, given a predicted equilibrium distribution of $\underline{\underline{m}}$ $=\left(m_{1}, m_{2}, m_{3}\right)=(7,6,5)$ for Game 1 and an observed distribution of choices $\underline{\underline{n}}=\left(n_{1}, n_{2}, n_{3}\right)=$ $(10,7,1)$, three subjects choosing location $j=1$ and one choosing location $j=2$ ought to switch their choices to location $\mathrm{j}=3$ to achieve equilibrium. Consequently, the measure of proximity in this case is $4^{3}$

The minimum number of switches required for achieving perfect coordination, denoted MinS, was computed for each iteration $t(t=1,2, \ldots, 16)$. The resulting values are presented on the top of each game matrix in Tables 2A and 2B. Figure 1 displays a 5-trial moving average of the MinS scores by game and group. The MinS scores are seen to range between 1 and 3; they indicate a close proximity to the predicted pure strategy equilibrium. ${ }^{4}$ Figure 1 indicates a group effect, with Group 2 exhibiting better coordination than Group 1 in Games 1, 2, and 6. There is also an indication of a systematic improvement in coordination over time for Group 1 in Games 1, 3, and 5.

-- Insert Fig. 1 about here --

To test for group, game, and replication effects, we divided the 96 trials of each group into 4 blocks of 24 trials each, with each block representing 4 replications of each of the 6 games. We

3 This measure is simply the sum of the number of over-subscribes. It is equivalent to (1/2) $\Sigma\left|n_{j}-m_{j}\right|$. 4 Given the parameters of the six games (Table 1), the mean MinS score over the six games is 15.3 . 
then subjected the $192 \mathrm{MinS}$ scores ( 96 for each group) to a $2 \times 4 \times 6$ group by block by game ANOVA with repeated measures on the block and game factors. The ANOVA yielded a significant group main effect $(F(1,36)=8.36, p<0.001)$. As suggested by Fig. 1, the mean MinS score of Group 2 (1.68) was significantly smaller than the mean of Group 1 (2.07). The ANOVA also yielded a significant game main effect $(F(5,36)=12.16, p<0.001)$. The Newman-Keuls post-hoc analysis shows no differences between Games 1, 2, 3, 4, and 5. The significant main game effect is entirely due to Game 6 for which the MinS score (0.719) is significantly smaller than the mean scores of the other five games $(1.875,2.187,2.219,2.000,2.250$, for Games 1 to 5 , respectively). Although the mean MinS scores decreased across blocks (3.500, 2.063, 1.708, 1.667 for Blocks 1, 2, 3 and 4, respectively), the trend was not significant $(F(3,34)=2.32, p=0.093)$. The interaction between group and blocks was also not significant $(F(3,34)=2.40, p=0.085)$. Neither of the other two-way interaction effects nor the single three-way interaction effect were significant.

Table 4 presents the means and standard deviations of the number of entries in each location in the 16 iterations. The means and standard deviations of the MinS scores are presented on the two right-hand columns. The results are shown separately by game and group. Also presented in the table are the expected number of entries for both the pure and mixed strategy equilibria, the associated standard deviations under the mixed strategy equilibrium, and the expected numbers and standard deviations of the MinS score with respect to the mixed strategy equilibrium.

$$
\text { -- Insert Table } 4 \text { about here -- }
$$

The results in Table 4 show a remarkable level of coordination. The null hypothesis that the observed and expected number of entries is equal cannot be rejected at the 0.05 level for all games and locations of Group 2. In Group 1, the only exceptions are locations 2 and 3 in Game $3(z=-$ 
3.135 and 2.668, respectively, $p<0.05)$ and location 1 in Game $4(z=2.328, p<0.03)$. Shifting attention to the MinS score, the hypothesis that the observed and expected (based on the mixed strategy equilibrium) scores are the same can not be rejected at the 0.05 level in both groups for Games, 3, 4, and 5. The MinS score is significantly smaller than expected in Games 1 and 6 of Group $1(\mathrm{z}=1.69, \mathrm{p}<0.05,4.77, \mathrm{p}<0.01$, for Games 1 and 6 , respectively), and higher in Game $3(\mathrm{z}=-1.766, \mathrm{p}<0.04)$. The MinS score is smaller than expected for Games 2 and 6 of Group $2(\mathrm{z}$ $=2.531, \mathrm{p}<0.01,50.00, \mathrm{p}<0.0001$, for (Games 2 and 6 , respectively).

\section{Model Testing}

This section reports the results of testing three individual level models that are designed to account for the high level of coordination observed in both groups. The first model is based on a simple coordination convention, the second is the mixed strategy equilibrium, and the third postulates commonly shared choice probabilities that are individually perturbed.

\section{A Coordination Model Based on Convention}

We propose two variants of a model that can yield, in principle, a high level of coordination. For a given location $j$, denote by "+", "“-", and " 0 " the cases where $n_{j}>m_{j}, n_{j}<m_{j}$, or $n_{j}=m_{j}$, respectively. If coordination is achieved (i.e., the location vector is characterized as 000 ), then all players are awarded the prize g. Deviation from equilibrium play results in one of three outcome patterns, namely, (+0-), (+--), and (++-) up to permutation of these indices. Whenever $n_{j} \leq m_{j}$ (denoted by "-" or " 0 "), each of the $n_{j}$ players receives the prize g. However, if $n_{j}>m_{j}$ (case "+"), only $m_{j}$ players are awarded the prize $g$ and the remaining $n_{j}-m_{j}$ players are awarded zero. The model assumes that the allocation of prizes on iteration $t(t=1,2, \ldots, 16)$ serves as a coordination device for the next time the same game $\mathrm{G}(\mathrm{G}=1,2, \ldots, 6)$ is played (by the same players). It does so by identifying the subset of the subjects who are not rewarded as the "excess 
demand" in the game (Mehta et al., 1994). We propose two variants of the coordination model that impose different requirements on the subjects' memory of the outcome of the previously played game G.

Version 1 - Memory is limited to the last iteration of game G. It assumes that a player can recall (with no error) his own choice and whether or not he was rewarded on that iteration.

Version 2 - In addition to the memory required by version 1, a player is assumed to recall the qualitative status of each of the other two locations in the previous iteration of game $\mathrm{G}$ as either "0", “"“, or "“+".

A reasonable convention would be for a player who was rewarded on entering location $j$ of game $G$ in iteration $t$ to repeat entering the same location $j$ on iteration $t+1^{5}$, and for a player who was not rewarded on iteration $t$ to enter a different location on iteration $t+1^{6}$. The two versions of the model differ as to the manner by which a non-rewarded subject chooses the entry location on iteration $\mathrm{t}+1$.

Version 1 - A non-rewarded subject on iteration $t$ is equally likely to switch to any of the other two locations on iteration $t+1$.

Version 2 - A non-rewarded subject on iteration $t$ is more likely to switch to a "-" location on iteration $\mathrm{t}+1$. If, however, both other locations are of type "-“", then version 1 holds.

Testable Implications. The convention model implies several testable hypotheses:

- Once perfect coordination is achieved, it will be preserved in all subsequent iterations of game G.

5 On the average, six trials separated any two iterations of the same game.

6 We propose this convention for a pure coordination game. If, for example, we change Game 5 from $\mathbf{g}=(2,2,2)$ and $\underline{m}=(12,4,2)$ to $\underline{g}=(4,5,6)$ and $\underline{m}=(12,4,2)$, the pure strategy equilibrium does not change and the task can again be interpreted as partitioning the group into three subgroups of 12,4 and 2 members. However, if coordination is achieved, subjects do care to which subgroup they belong and may object to the convention suggested above. Rather, 
- Under a strong interpretation of the model (both versions), subjects will always switch location after not being rewarded and never switch after being rewarded. Under a weak interpretation, switching is more likely to occur following no reward than reward on the previous iteration.

- Version 2 makes a specific prediction as to the exact location that will be chosen, given that a switch occurs.

These hypotheses are clearly rejected by the data. Turning to the first hypothesis, Tables $2 \mathrm{~A}$ and 2B show that (perfect) coordination was achieved only six times in Group 1 (once in Game 3, twice in Game 4, and three times in Game 6) and fifteen times in Group 2 (twice in Games 1, 2, and 4, once in Game 4, and eight times in Game 6). However, only once in Group 1 (Game 6) and four times in Group 2 (Games 1, 4, and 6) was coordination achieved on at least two consecutive iterations of the same game. The longest string of coordination on successive iterations occurred on Game 6 of Group 2. However, this string was interrupted three times before the last iteration. Even in those cases where coordination was achieved twice in a row, it was not the case that all the 18 players chose the same location on the two successive presentations (see Ochs 1990 for similar results). For example (Table $2 \mathrm{~B}$ ), we observe coordination on the $10^{\text {th }}$ and $11^{\text {th }}$ iterations of Game 1 played by Group 2. Yet, nine of the eighteen players changed their location choice between these two iterations of Game 1 (with switched decisions canceling one another).

Thus, we find no evidence for the prediction that players who were awarded the prize on game $G$ would not switch their decisions on the next iteration of the same game. Even the considerably weaker prediction that subjects not awarded the prize on game $\mathrm{G}$ will be more likely to switch than stay on the same location the next time game $G$ is presented is rejected for most subjects. Tables 
5A and 5B present the relevant individual data for Groups 1 and 2, respectively. The two columns under the label "Not Rewarded" present the number of times. after not being rewarded on iteration $t$, a subject chose the same location on iteration $t+1(=)$, and the number of times a different location was chosen $(\neq)$. The corresponding choice frequencies after a reward was provided on iteration $t$ are presented under the "Rewarded" label (ignore for now the three subcategories, $n_{t}>$ $m_{t}, n_{t}=m_{t}$, and $n_{t}<m_{t}$, and aggregate the frequencies for $=$ and $\neq$ ). A square in the table indicates that the proportion of switching after no reward is significantly higher than after reward at the 0.1 significance level. The above hypothesis is supported by seven subjects of Group 1 and eight of Group 2. For other subjects, it is not even the case that switching is more likely to occur after no reward than after a reward. Note, however, that the frequency of not being rewarded was rather low. On average, subjects were rewarded on $88 \%$ and $91 \%$ of trials, for Groups 1 and 2 , respectively. The lowest reward level was 79\% for subject 5 of Group 1 and $78 \%$ for subject 1 of Group 2. Consequently, the test for equality of proportions at the individual level is based on relatively small frequencies. However, The overall trend is as predicted: in Group 1 (2) 66\% (70\%) of the time the same location was chosen after receiving a reward compared to only $48 \%(47 \%)$ of the time after not receiving a reward.

-- Insert Tables 5A and 5B about here --

Version 2 makes a specific prediction as to the exact location that is chosen if a switch occurs. The model predicts that given a switch-out from location $a\left(j_{t}=a\right)$, then if $\left(n_{b(t)} \leq m_{b}\right.$ and $\left.n_{c(t)}>m_{c}\right)$ or $\left(n_{b(t)}<m_{b}\right.$ and $\left.n_{c(t)}=m_{c}\right)$ the switch is more likely to be made to location $b$; otherwise, it is as likely to be made to location $b$ as to location $c$. The last two columns of Tables 5A and 5B present the frequencies of switches that either support $(\beta)$ or contradict $(Q)$ the above hypothesis, given that one of the above conditions holds. A diamond indicates that the null hypothesis that the switch 
(under these conditions) is as likely to be to any of the other two locations is rejected at the 0.05 level. Tables 5A and 5B indicate that only four subjects from Group 1 and seven from Group 2 rejected the null hypothesis. As before, the overall trend is as predicted.

The most troublesome finding for the coordination model is the relatively high frequency of switching after a reward. Why do subjects switch location after being rewarded for their choice on the previous iteration of the same game? One possible factor that might affect subjects' decision to switch out from location $a\left(j_{t}=a\right)$ on iteration $t+1$ is the qualitative relationship between $n_{j}$ and $m_{j}$ on time $t$. The rational is as follows: if $n_{j} \leq m_{j}$, then the subject is rewarded and no luck is involved in the award. The subject may attribute his reward in this case to his "smart" choice. However, if $n_{j}>m_{j}$, even if a reward is awarded, the subject may attribute his reward to luck. Consequently, independent of the reward, $P\left(j_{t} \neq j_{t+1} \mid n_{j}>m_{j}\right)>P\left(j_{t} \neq j_{t+1} \mid n_{j} \leq m_{j}\right)$. Tables 5A and 5B present the relevant frequencies under the $n_{t}>m_{t} n_{t}=m_{t}$, and $n_{t}<m_{t}$ labels (aggregate the frequencies for $n_{t}>m_{t}$ under both the reward and no reward columns for this analysis). A circle between the $n_{t}>m_{t}$ and $n_{t}=m_{t}$ columns indicates that the alternative hypothesis $P\left(j_{t} \neq j_{t+1} \mid n_{j}>m_{j}\right)$ $\leq \mathrm{P}\left(\mathrm{j}_{\mathrm{t}} \neq \mathrm{j}_{\mathrm{t}+1} \mid \mathrm{n}_{\mathrm{j}} \leq \mathrm{m}_{\mathrm{j}}\right)$ is rejected at the 0.05 level. Tables $5 \mathrm{~A}$ and $5 \mathrm{~B}$ show that the alternative hypothesis was rejected by three subjects of Group 1 and ten subjects of Group 2. However, as before, the overall trend is as predicted.

\section{Mixed Strategy Equilibrium Play.}

Table 3 reveals that the mixed strategy equilibrium solution for risk-neutral players cannot account for our results. For example, six subjects of Group 1 and eight subjects of Group 2 chose location $\mathrm{j}$ $=1$ in Game 5 at least 14 of 16 times $(87.5 \%)$, in contrast to the equilibrium probability of play which is equal to 0.743 . Similarly, six subjects of Group 1 and five subjects of Group 2 chose location $\mathrm{j}=1$ in Game 4 at least 14 out of 16 times, compared to the equilibrium probability of 
0.596. The assumption that all the subjects followed the mixed strategy equilibrium under the assumption of risk-neutrality is not supported.

A considerably weaker hypothesis asserts that the subject's 16 decisions in the same game G constitute a random sequence generated by probabilities $p_{1}, p_{2}$, and $p_{3}\left(p_{1}+p_{2}+p_{3}=1\right)$ of entering locations $\mathrm{j}=1, \mathrm{j}=2$, and $\mathrm{j}=3$, respectively. We impose no further constraints on these three probabilities and allow them to vary from one player to another. The interpretation of this hypothesis is that each subject has stable propensities to enter each of the three locations in each of the six games, and that these propensities may vary across subjects and games, but for a given subject they are not adjusted over time. Table 6 presents cumulative probability distributions that a random sequence containing $r_{j}$ elements of type $j$ will generate $R$ runs in a sequence of 16 decisions. With $\mathrm{J}=3$ and 16 replications, there are 30 possible sequences ${ }^{7}$ presented as rows in Table 6. The non-shaded areas in the table present an $80 \%$ symmetric confidence interval for the hypothesis that the sequence is randomly generated.

-- Insert Table 6 about here --

The hypothesis of randomly generated sequences was tested separately on the individual level for each game. Tables $2 \mathrm{~A}$ and $2 \mathrm{~B}$ (second column) show the games for which the number of runs falls outside the confidence interval for a given subject. A (black) circle containing the number 1 indicates that the hypothesis of a randomly generated sequence is rejected at the 0.01 significance level. The numbers $2,3,4$, and 5 correspond to significance levels of $0.10,0.2,0.3$, and 0.4 , respectively (all the tests are two-tailed). Even at the most liberal level of significance of $40 \%$, that permits a relatively easy rejection of the null hypothesis, only 36 of the $108(18 \times 6)$ sequences in

7 Note that types are interchangeable for this test. For the test purpose, the following two outcomes are equivalent: (11 in location 1, 3 in location 2, and 2 in location 3) and (3 in location 1,11 in location 2, and 2 in location 3 ). 
Group 1 and 28 of the sequences in Group 2 reject the null hypothesis. Using a wider and more common confidence interval of $90 \%$, only 12 of the 108 choice sequences of Group 1 and 11 of the 108 sequences of Group 2 are rejected as non-random. Table 3 presents the choice sequences not rejected by the null hypothesis by subject and game (for a $60 \%$ confidence interval). It shows a moderate degree of support for the very weak null hypothesis that most of the subjects randomized their location choices with probabilities $p_{1}, p_{2}$, and $p_{3}$ that might vary across games and within a game across subjects.

These findings give rise to three questions. First, how can such random behavior on the individual level generate the high level of coordination observed on the group level? Second, how sensitive is the group coordination to the heterogeneity of the subjects in their propensity to enter each location? Third, can an aggregation of random strategies account for the group level effects of reward and of over- and under-subscription on switching behavior?

\section{A Choice Model with Randomly Perturbed Probabilities}

The next model that we propose assumes that all the individual propensities to enter location $\mathrm{j}$ emerge from a single set of three probabilities, but differ from one another due to random perturbation. Our point of departure is the intuitive case where all 18 subjects enter each location with a probability that is proportional to the number of prizes: $p_{j}=m_{j} / \Sigma m_{j}^{8}$. The issue that we set to investigate is how much "noise" can we introduce and still achieve a satisfactory level of coordination. To answer this question, we perturbed these three probabilities in the following way. Denote the probability of player i choosing location i by $p_{i j}(j=1,2,3)$. We simulated the following process. First, for each simulated subject i we randomly selected three probabilities from

8 Note that these are the probabilities that minimize MinS, and not the probabilities that are prescribed by the mixed strategy equilibrium. 
the intervals $\left[\max \left(0, p_{j}-d\right), \min \left(1, p_{j}+d\right)\right]$ such that $\Sigma p_{i j}=1$. We used a uniform distribution for each interval. Next, a location was randomly selected for each subject based on his own individual probabilities. Given the 18 choices, the MinS scores were then computed (with respect to the pure strategy equilibrium). To find the expected MinS for a given d, the process was repeated 10,000 times. The larger the $d$, the larger the heterogeneity of the 18 simulated subjects. Further, as $d$ approaches 1 the mean probability of entry in each location (across the 18 subjects) approaches $1 / 3$.

Figure 2 presents the mean simulated MinS scores for various levels of $d$. As might be expected, the higher the heterogeneity of the simulated subjects, the larger is the expected deviation from coordination. Second, and again as might be expected, games with relatively flat distribution of prizes in the three locations are less sensitive to population heterogeneity. In particular, given 18 randomly selected probability distributions over the three locations in Game 1, good coordination is expected. The observed MinS scores for the six games (over the two groups) were between 0.56 and 2.88. Figure 2 shows that such results would be expected, given choice probabilities that deviate from the "intuitive" probabilities $\mathrm{p}_{\mathrm{j}}$ by about \pm 0.2 .

-- Insert Figure 2 about here --

Finally, we investigate the possibility that an aggregation of random strategies (with $d=0.2$ ) would produce the group level regularities reported in Section 3. Recall that we found three significant group level effects:

- $\mathrm{P}($ switch $\mid$ reward $)<\mathrm{P}($ switch $\mid$ no reward $)$.

- Given a switch-out from location a $\left(\mathrm{j}_{t}=\mathrm{a}\right)$, if $\left(\mathrm{n}_{\mathrm{b}(\mathrm{t})} \leq \mathrm{m}_{\mathrm{b}}\right.$ and $\left.\mathrm{n}_{\mathrm{c}(\mathrm{t})}>\mathrm{m}_{\mathrm{c}}\right)$ or $\left(\mathrm{n}_{\mathrm{b}(\mathrm{t})}<\mathrm{m}_{\mathrm{b}}\right.$ and $\left.n_{c(t)}=m_{c}\right)$ then $P\left(j_{t+1}=b\right)>P\left(j_{t+1}=c\right)$.

- $P\left(j_{t} \neq j_{t+1} \mid n_{j}>m_{j}\right)>P\left(j_{t} \neq j_{t+1} \mid n_{l} \leq m_{j}\right)$. 
To investigate this possibility, we simulated 10,000 group level results based on 18 simulated subjects (in each group) that enter each location with a perturbed probability of $\mathrm{p}_{\mathrm{j}}=\mathrm{m}_{\mathrm{j}} / \Sigma \mathrm{m}_{\mathrm{j}} \pm 0.2$ (under the restriction $\Sigma \mathrm{p}_{\mathrm{ij}}=1$ ) for the 6 games and 96 trials as in our design.

Table 7 presents the proportions of simulated trials from replications 1 to 15 that were either rewarded or not rewarded by location ${ }^{9}$. Similar to our data, the frequency of no reward trials is rather low (11.6\%). Note, however, that the probability of reward is a function of the exact location (\% column). The probability of reward decreased from 0.921 to 0.852 to 0.801 for locations 1,2 and 3, respectively. Given a reward observation, it is much more likely to come from $\mathrm{j}=1$ than from $\mathrm{j}=2$ or 3 (\% row - the probabilities are 0.610 vs. 0.391$)$. However, given a no reward observation, it is more likely to come from locations $\mathrm{j}=2$ or $\mathrm{j}=3(0.601)$ than from $\mathrm{j}=1$ (0.399). Given that the high propensity location is more likely to be repeated (randomly), this pattern demonstrates that an aggregation of random strategies can produce data that are consistent with the hypothesis that it is more likely to switch after no reward than after reward.

-- Insert Table 7 about here --

Table 8 presents the results of the simulation with regard to the proportion of games on which capacity met $(=)$, exceeded $(<)$ or fell short of demand $(>)$ by location. Over all games, location 1 was over-subscribed $57.8 \%$ of the time. The proportions of over-subscription in locations 2 and 3 were much lower. However, the interesting pattern relates to the fact that in the simulation (as well as in our data) location 2 was much more likely to be under-subscribed $(65.6 \%)$ than the other two locations. Since location 1 was selected most often, most of the switch-out observations occurred after location 1 was chosen. Because a random switch (if it occurs) is more likely to occur to location 2 than location 3 , coupled with the fact that location 2 
was more often under-subscribed, the observed pattern of switching to the under-subscribed location is generated at the group level by our simulated subjects.

-- Insert Table 8 about here --

The only pattern of group behavior that could not be reproduced in the simulation is the finding that subjects are more likely to switch on iteration $t+1$ after their location decision on iteration $t$ was over-subscribed. A random strategy that makes it more likely to select a high capacity location $\left(\mathrm{p}_{1}>\mathrm{p}_{2}>\mathrm{p}_{3}\right)$ will predict that switching will occur much more often after selecting the low capacity compared to the high capacity location. However, the simulation shows that the low capacity locations are the ones that are less likely to be over-subscribed. Hence, the finding that switching decision is more likely to occur after the location is over-subscribed was not replicated by the simulation.

\section{Discussion}

We set out to investigate large group coordination in six different pure coordination games that were repeated over time in a random order. For each of these games, perfect coordination would have eliminated the outcome uncertainty. Given the simplicity of the task, we expected that a high level of coordination would be achieved through some simple adaptation process. Our results seem to reject this hypothesis. Although a high level of coordination was achieved, we found no significant trends in the data across trials. Nor could we support the hypothesis that the frequent switching in choice of location was due to adaptation at the individual level. Rather, switching could be accounted for by commonly shared but individually perturbed choice probabilities. The important message is that the data should be carefully scrutinized in order not to fall into several possible traps, where a simple random process with "noise" can by its very nature produce what

\footnotetext{
${ }^{9}$ Replication 16 did not contribute data to the switching ansis.
} 
seems to be "sophisticated" adaptation behavior.

We do not argue that all the subjects behaved randomly all the time. The data clearly refute this statement. For example, we could not rule out as an artifact the finding that some subjects are more likely to switch out from a location for which demand exceeds supply. Further, it is quite clear that even across games, subjects did not exhibit consistent behavior, where in one game one pattern emerged but not in others. The question is at what level of detail should we explain the subjects' choices? Identifying clusters of subjects who behave similarly is probably the most practical approach. We have tried unsuccessfully to follow this approach in our study. However, it turned out that this was not necessary because at the simplest level all subjects could be clustered into one group described by a mixed strategy with perturbed choice probabilities. We conjecture that although other adaptation processes might take place, in our task their contribution to explaining individual level behavior is negligible

We only investigated heterogeneity of the group members at a very simple level of deviation from an underlying set of choice probabilities. The larger the group, the higher the heterogeneity that can be tolerated in our task. Such heterogeneity makes sense if the original choice probabilities are common to all players. We argue that this, indeed, is the case in our no-conflict coordination game. We do not expect this property to hold in all coordination games. On the contrary, whenever coordination elicits conflict, we believe that other considerations such as fairness and envy enter subjects' thoughts in different ways such that the assumption of common choice probabilities is probably no longer valid. This is why, for example, Zwick et al. (1999) found a low level of coordination in a market entry game that elicited conflict, whereas Rapoport et al. (1998) reported remarkably good coordination in a market entry game with no conflict. 


\section{Acknowledgement}

This research has been supported by a grant from the Hong Kong Research Grants Council (Project No. CA98/99.BM01). 


\section{References}

Mehta, J., Starmer, C., and Sugden, R. (1994). Focal points in pure coordination games: An experimental investigation. Theory and Decision, $\underline{36}, 163-185$.

Ochs, J (1990). The coordination problem in decentralized markets: An experiment. Quarterly Journal of Economics, $105,545-559$.

Rapoport, A.. Lo, Alison K. C., and Zwick, R. (2000). Choice of Prizes Allocated by Multiple Lotteries with Endogenously Determined Probabilities. HKUST working paper.

Schelling, T. (1978). Micromotives and Macrobehavior. New York: W. W. Norton.

Weber, R. A. (2000). 'Learning' with no feedback in a competitive guessing game. Working paper. Social and Decision Sciences, Carnegie Mellon University.

Young, H. P. (1994). Equity. Princeton: Princeton University press.

Zwick, R. and Rapoport, A. (1999). Tacit Coordination in a Decentralized Market Entry Game with Fixed Capacity. HKUST working paper. 


\section{Figure 1}

Five-Trial Moving Average of Deviation from Pure Strategy Equilibrium

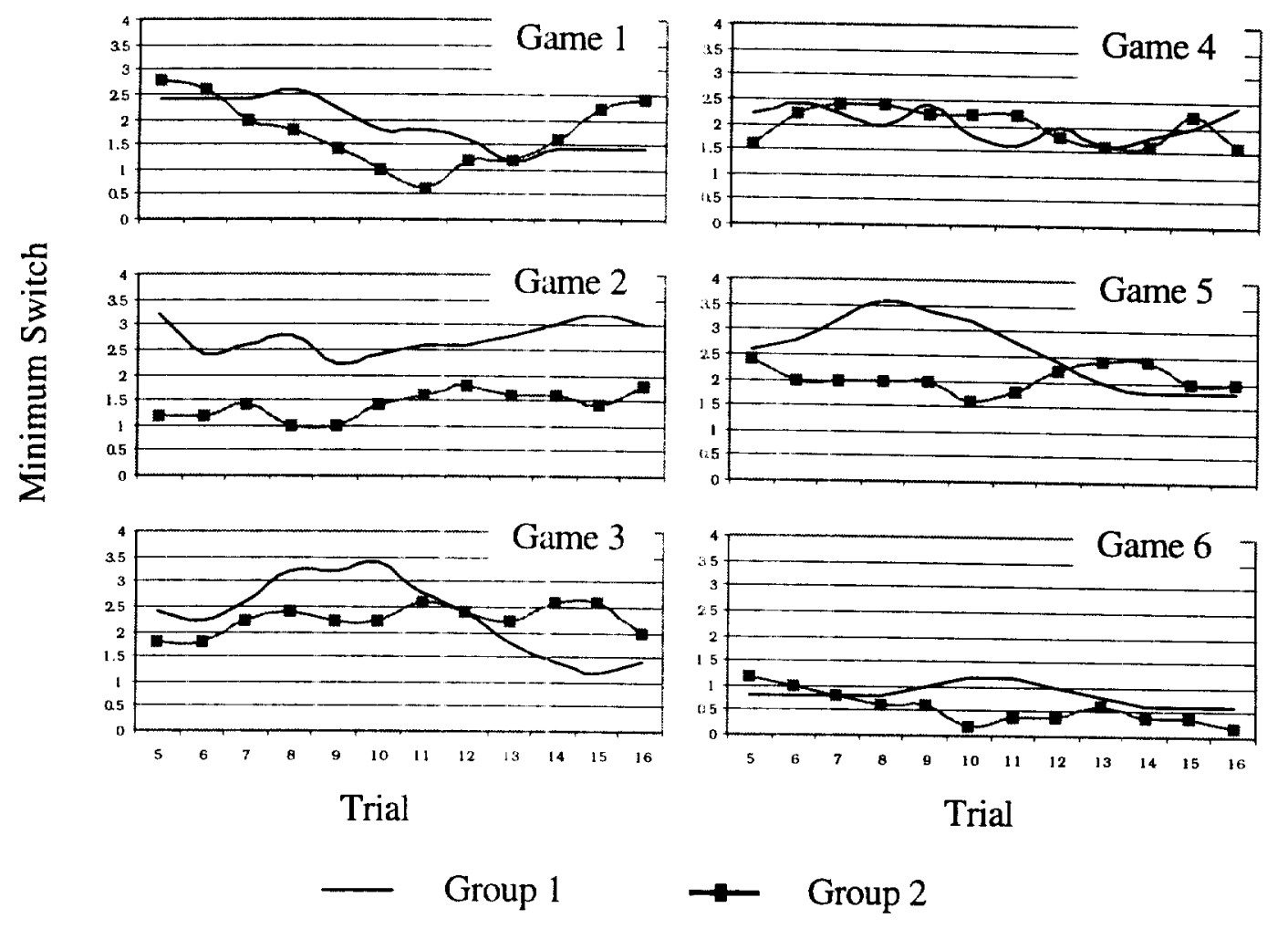


Figure 2

Expected MinS at various level of population heterogeneity in the propensity to enter each location

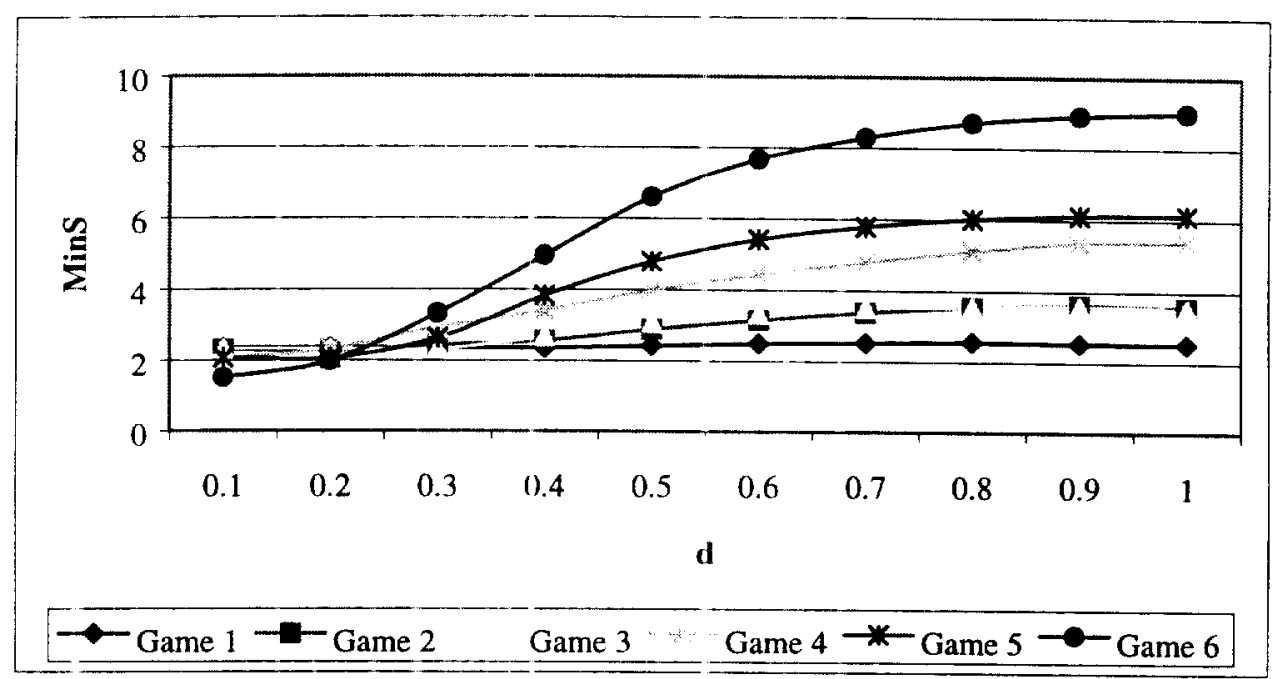


Table 1

Parameter Values and Equilibrium Solutions for the 6 games

\begin{tabular}{cccccccccccccc}
\hline & \multicolumn{3}{c}{$\begin{array}{c}\text { Prize } \\
\text { Values }\end{array}$} & \multicolumn{3}{c}{$\begin{array}{c}\text { Number of } \\
\text { Prizes }\end{array}$} & \multicolumn{3}{c}{$\begin{array}{c}\text { Pure Strategy } \\
\text { Equilibrium }\end{array}$} & \multicolumn{3}{c}{$\begin{array}{c}\text { Mixed Strategy } \\
\text { Equilibrium }\end{array}$} \\
\hline Game & $\mathrm{g}_{1}$ & $\mathrm{~g}_{2}$ & $\mathrm{~g}_{3}$ & $\mathrm{~m}_{1}$ & $\mathrm{~m}_{2}$ & $\mathrm{~m}_{3}$ & $\mathrm{n}^{*}{ }_{1}$ & $\mathrm{n}_{2}^{*}$ & $\mathrm{n}^{*}{ }_{3}$ & $\mathrm{q}_{1}$ & $\mathrm{q}_{2}$ & $\mathrm{q}_{3}$ \\
\hline 1 & 2 & 2 & 2 & 7 & 6 & 5 & 7 & 6 & 5 & .403 & .333 & .264 \\
2 & 2 & 2 & 2 & 8 & 7 & 3 & 8 & 7 & 3 & .470 & .400 & .130 \\
3 & 2 & 2 & 2 & 9 & 5 & 4 & 9 & 5 & 4 & .541 & .263 & .196 \\
4 & 2 & 2 & 2 & 10 & 7 & 1 & 10 & 7 & 1 & .596 & .389 & .015 \\
5 & 2 & 2 & 2 & 12 & 4 & 2 & 12 & 4 & 2 & .743 & .191 & .066 \\
6 & 2 & 2 & 2 & 15 & 2 & 1 & 15 & 2 & 1 & .928 & .059 & .013 \\
\hline
\end{tabular}


Table 2A

Game 1

Observed sequential choices by subjects, games, and trials - Group 1

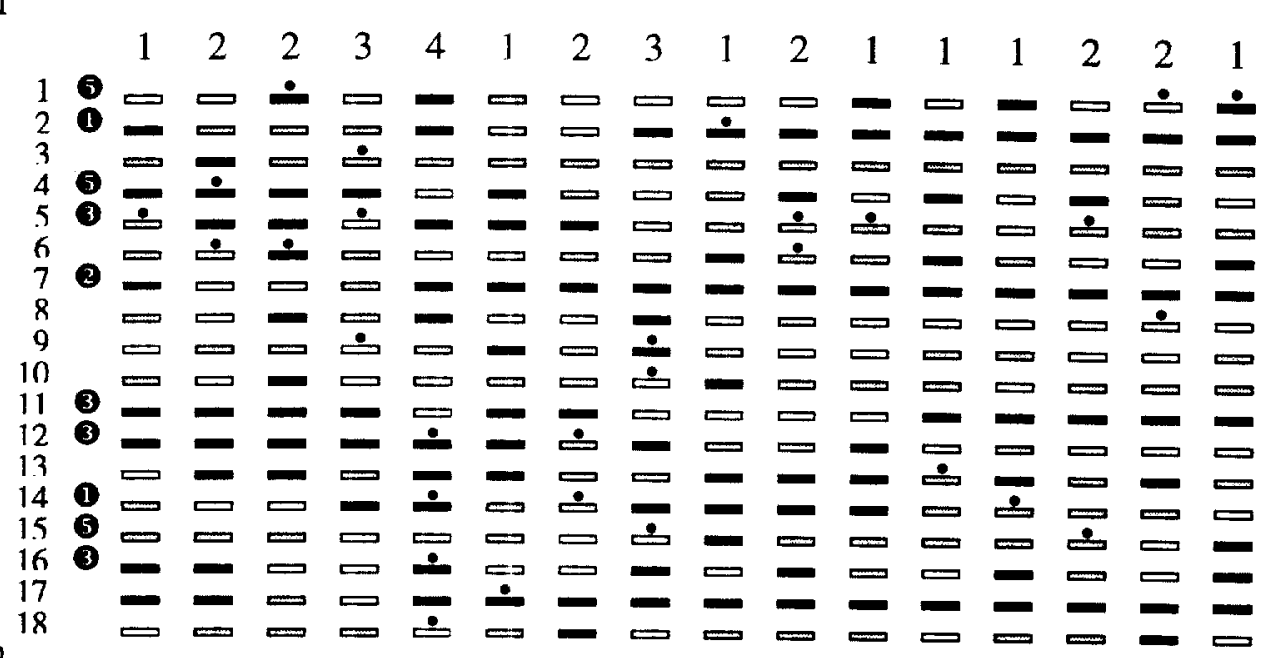

Game 2

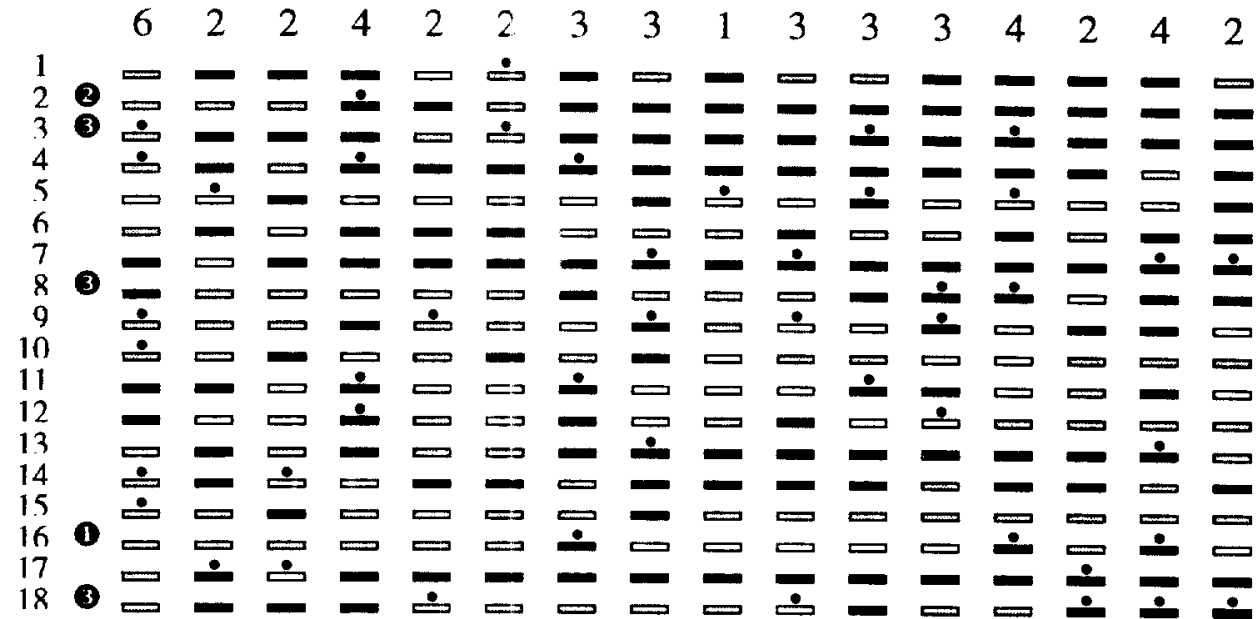

Game 3

\begin{tabular}{|c|c|c|c|c|c|c|c|c|c|c|c|c|c|c|c|c|}
\hline & 5 & 2 & 2 & 2 & 1 & 4 & 4 & 5 & 2 & 2 & 1 & 2 & 2 & 0 & 1 & 2 \\
\hline & 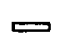 & ש & ح & $\Longrightarrow$ & r & ᄃ & $\Longrightarrow$ & $\square$ & $\square$ & & & ص & ᄃ & 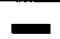 & $=$ & \\
\hline & $=$ & & - & $=$ & $\bar{C}$ & - & 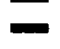 & & & & & $=$ & - & & & \\
\hline & & & & & & & & & & & & & & & & \\
\hline & 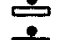 & 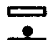 & $\div$ & $\square$ & - & 7 & $=$ & $\square$ & $\square$ & & & $\stackrel{2}{2}$ & & & & \\
\hline & $\Rightarrow$ & $=$ & & & & כ而 & & ש & & & & & - & 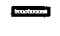 & & \\
\hline & - & 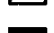 & 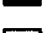 & - & & - & & & 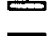 & & & & - & $-\infty$ & & \\
\hline & - & & & $\square$ & $=$ & 5 & 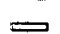 & 5 & $=$ & $m$ & $=$ & $=$ & 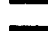 & $=$ & & \\
\hline 6 & $=$ & $\Longrightarrow$ & $\Longrightarrow$ & $\Longrightarrow$ & $=$ & 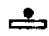 & - & $=$ & 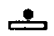 & $\square$ & 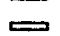 & ப் & 2 & $\hookrightarrow$ & 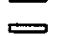 & \\
\hline & $\Longrightarrow$ & ص & $=$ & - & - & $=$ & $\stackrel{\bullet}{ }$ & - & $=$ & $\square$ & $=$ & - & $=$ & 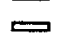 & $=$ & $=$ \\
\hline & $\dot{8}$ & 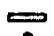 & - & $\Longrightarrow$ & $=$ & 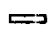 & $\dot{1}$ & $\Rightarrow$ & ש & של & $\Rightarrow$ & $=$ & - & 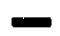 & 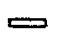 & 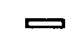 \\
\hline$\stackrel{2}{9}$ & $\Longrightarrow$ & b & & 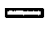 & 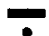 & $m$ & $\Longrightarrow$ & $\stackrel{0}{0}$ & $\Rightarrow$ & 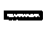 & $m$ & (س) & $=$ & $=$ & $\Rightarrow$ & $=$ \\
\hline 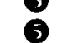 & & $\Rightarrow$ & = & - & & ᄃ & $=$ & $\doteq$ & - & - & $=$ & 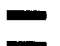 & 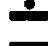 & $=$ & & \\
\hline & $\ddot{\square}$ & ש & & 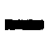 & $\rightleftharpoons$ & 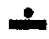 & $\Longrightarrow$ & s & 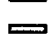 & $\doteq$ & $\Longrightarrow$ & $=$ & $=$ & $\Longrightarrow$ & $=$ & \\
\hline & & & & $\because$ & & - & $\stackrel{2}{*}$ & & $\Longrightarrow$ & & & $\boldsymbol{\theta}$ & $=$ & $\Rightarrow$ & & \\
\hline & & & & & & & & & & & & & & & & \\
\hline
\end{tabular}


Table 2A (continued)

Observed sequential choices by subjects, games, and trials - Group 1

Game 4

Game 5

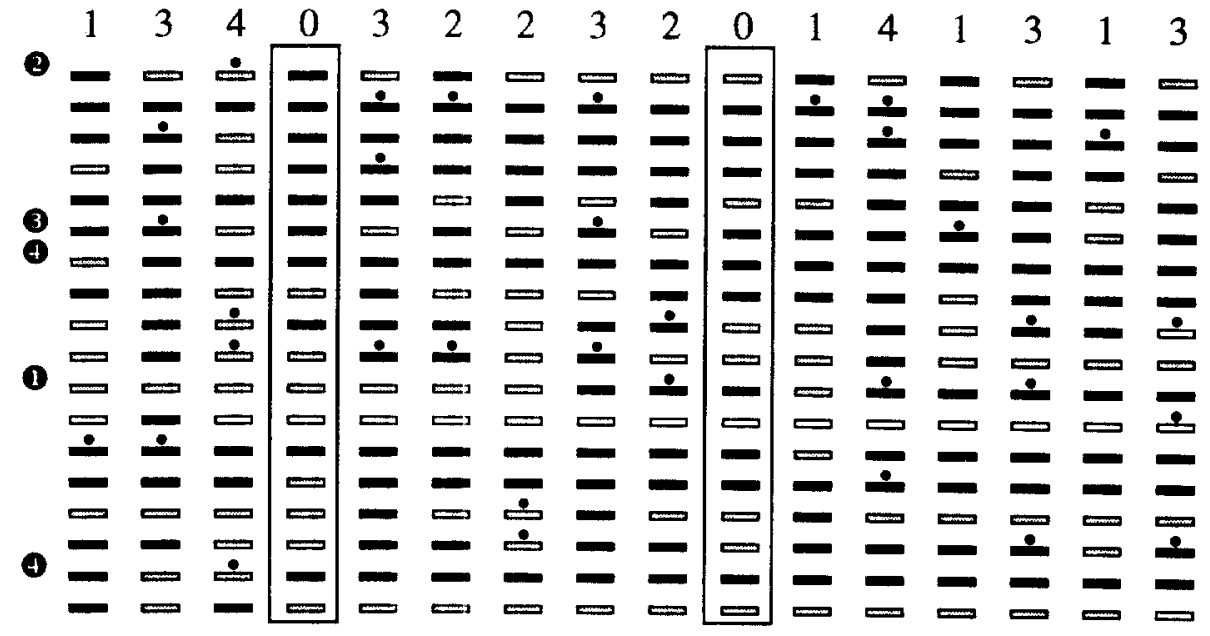

$$
\begin{array}{llllllllllllllll}
3 & 2 & 1 & 4 & 3 & 4 & 4 & 3 & 3 & 2 & 2 & 2 & 1 & 2 & 2 & 2
\end{array}
$$

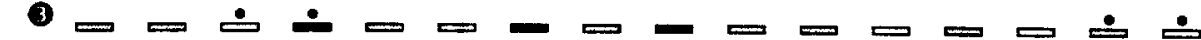
๑ ए

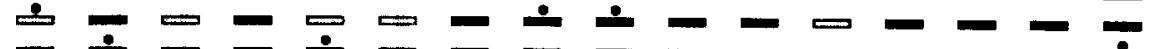
ए

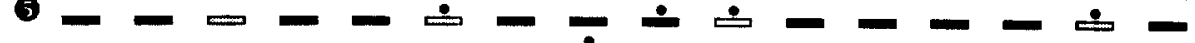
ए

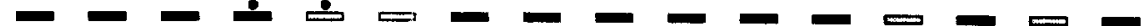

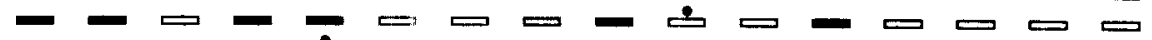
ए ए

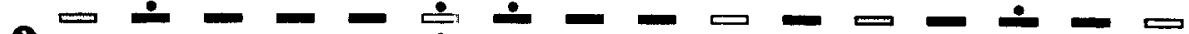

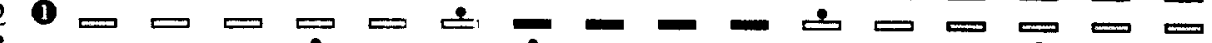

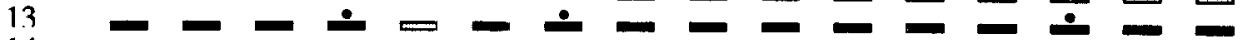

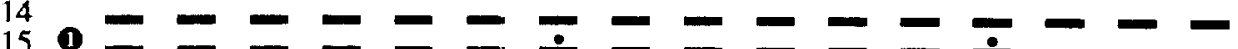
$150 \square-\square=\square \square \square \square \square \square$

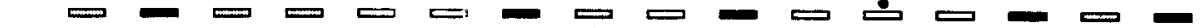

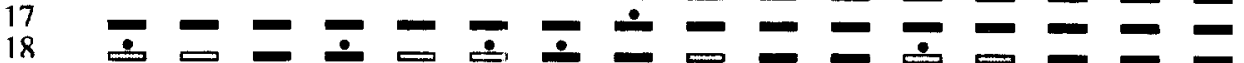
Game 6

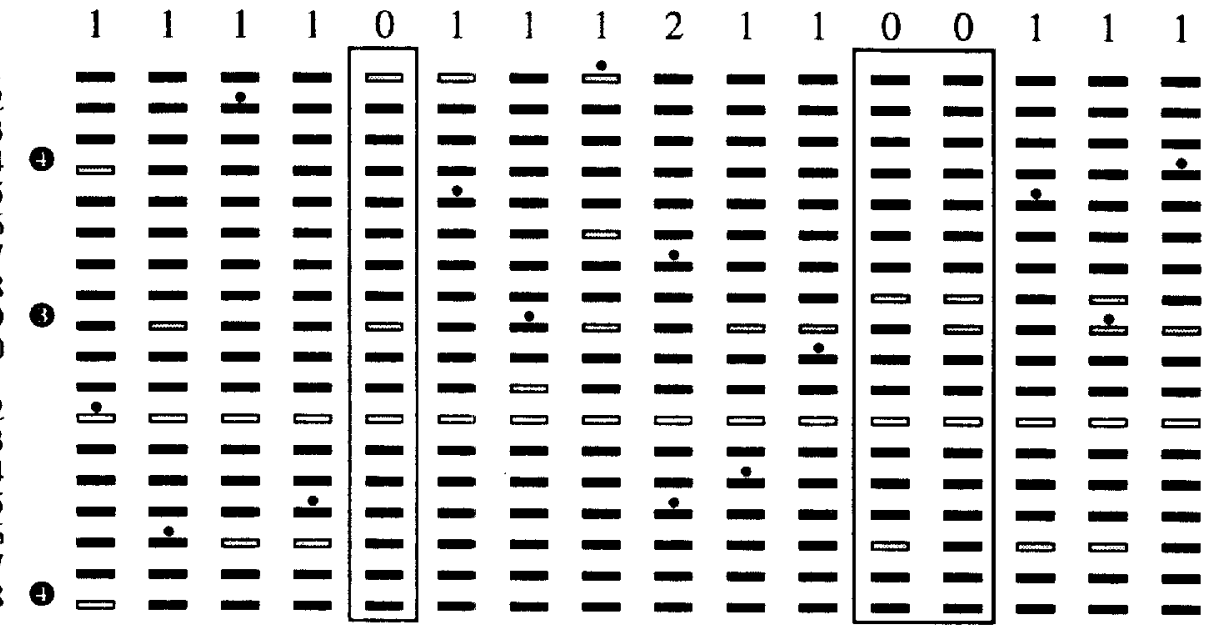


Table 2B

Game 1

Observed sequential choices by subjects, games, and trials - Group 2

Game 2

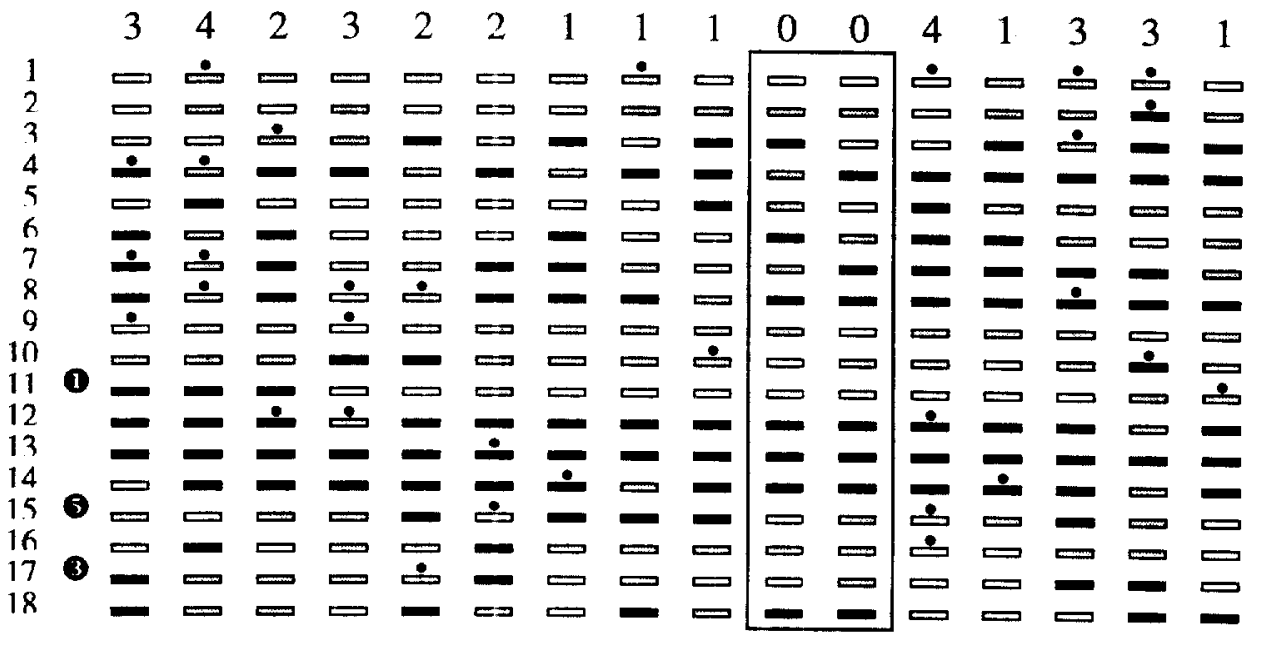

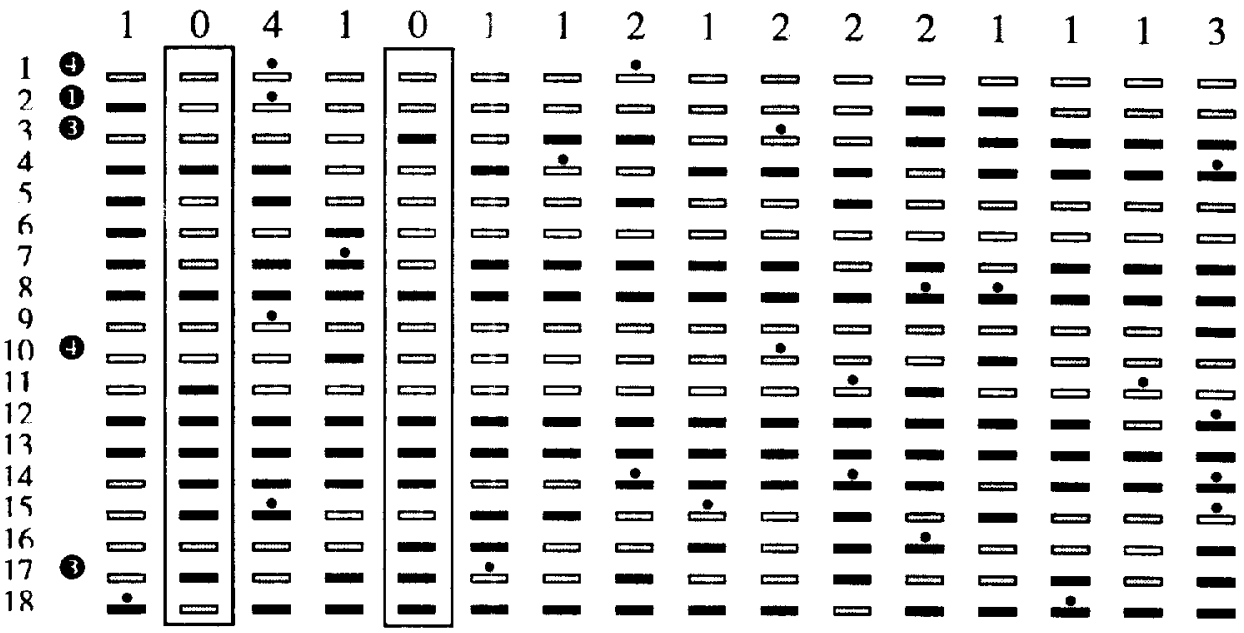

Game 3

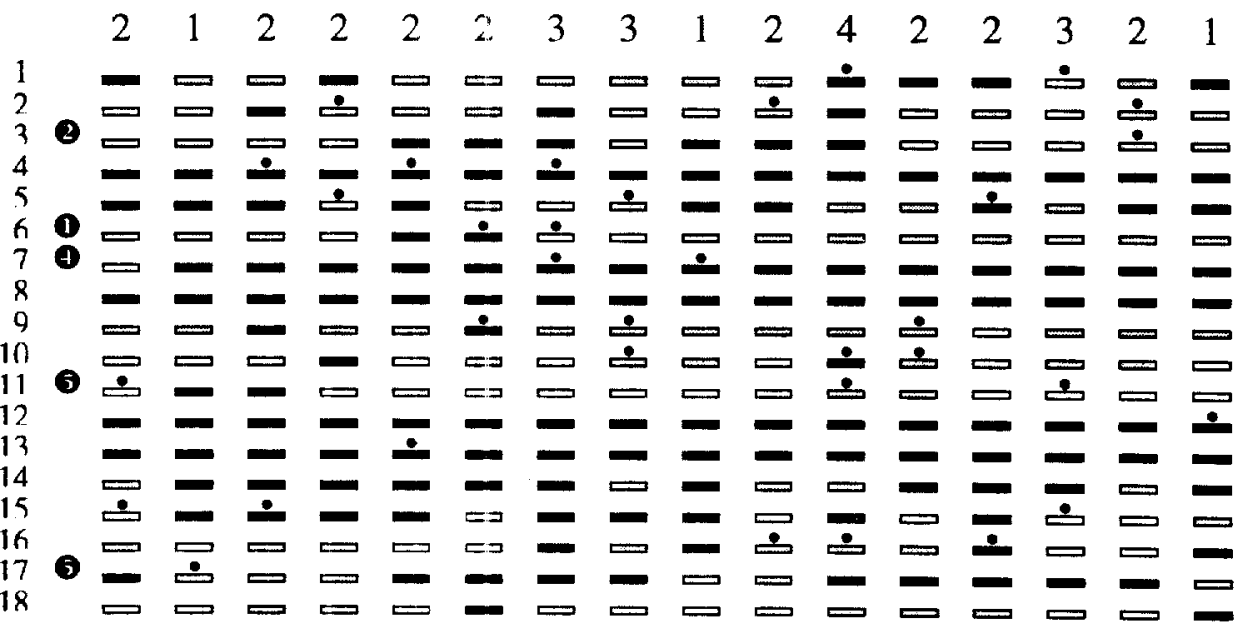


Table 2B (continued)

Game 4

Observed sequential choices by subjects, games, and trials - Group 2

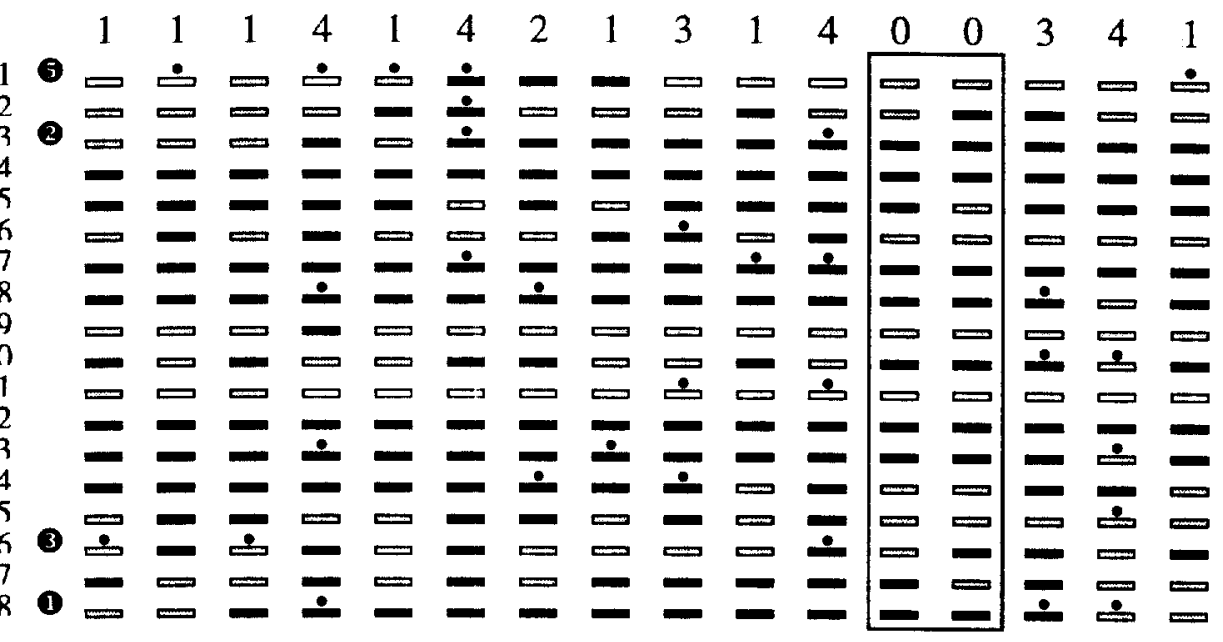

Game 5

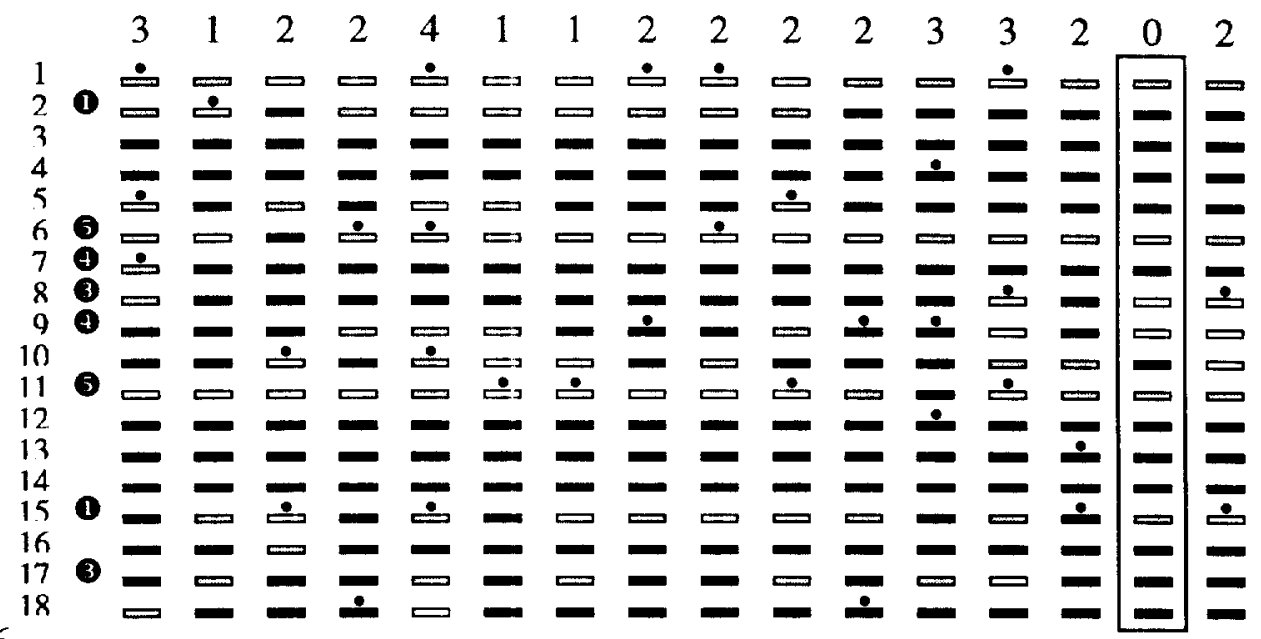

Game 6

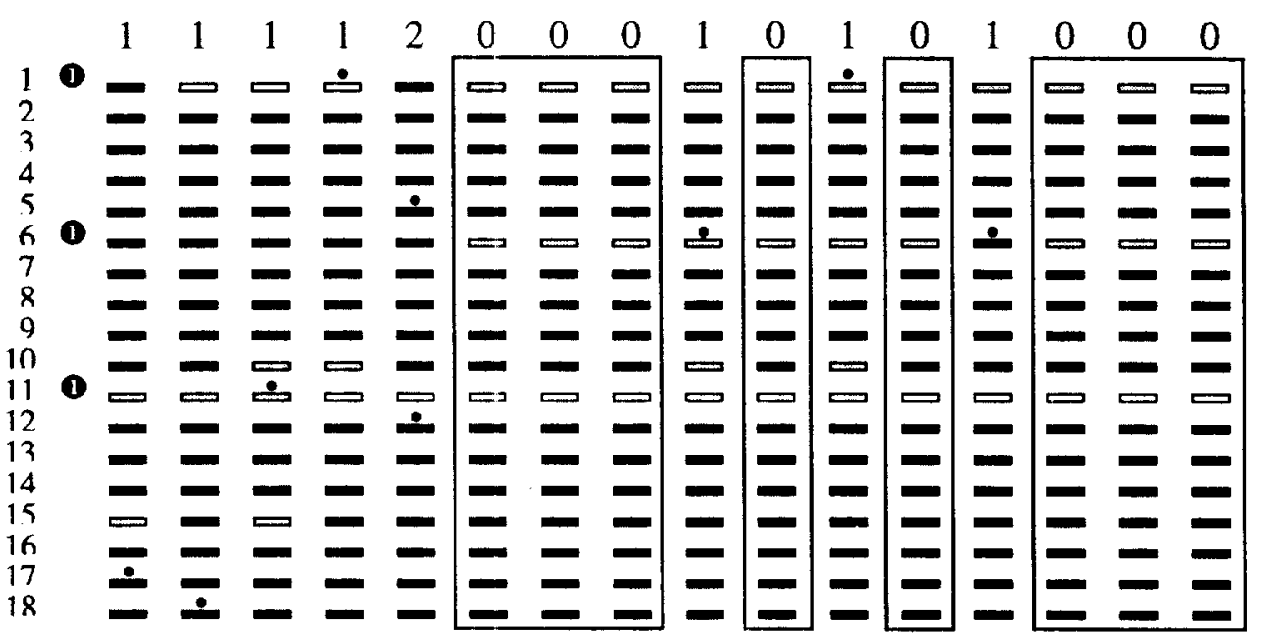


Table 3

Games with consistent behavior or behavior that are not distinguishable from a random sequence

\begin{tabular}{|c|c|c|c|c|c|c|}
\hline \multicolumn{7}{|c|}{ Group 1} \\
\hline & \multicolumn{6}{|c|}{ Game } \\
\hline $\mathrm{ID}$ & 1 & 2 & 3 & 4 & 5 & 6 \\
\hline 1 & & $x$ & $x$ & & & $x$ \\
\hline 2 & & & 0 & 0 & 0 & 0 \\
\hline 3 & $\bar{x}$ & & 0 & 0 & 0 & 0 \\
\hline 4 & & $\bar{x}$ & & $x$ & $x$ & 0 \\
\hline 5 & & $\bar{x}$ & $x$ & $x$ & $x$ & 0 \\
\hline 6 & $\bar{x}$ & $\bar{x}$ & & & & 0 \\
\hline 7 & & 0 & 0 & 0 & 0 & 0 \\
\hline 8 & $\bar{x}$ & & $\bar{x}$ & $x$ & & $\bar{x}$ \\
\hline 9 & $\bar{x}$ & $x$ & & $x$ & & \\
\hline 10 & $\bar{x}$ & $x$ & $x$ & $x$ & $x$ & 0 \\
\hline 11 & & $x$ & & & $x$ & 0 \\
\hline 12 & & $x$ & & $\bar{\square}$ & & $\square$ \\
\hline 13 & $\bar{x}$ & $x$ & & 0 & 0 & 0 \\
\hline 14 & & $x$ & & 0 & 0 & 0 \\
\hline 15 & & $\diamond$ & $x$ & $x$ & & 0 \\
\hline 16 & & & $x$ & $x$ & $x$ & $x$ \\
\hline 17 & O & 0 & & 0 & 0 & 0 \\
\hline 18 & $\bar{x}$ & & $x$ & $x$ & $\bar{x}$ & 0 \\
\hline
\end{tabular}

\begin{tabular}{|c|c|c|c|c|c|c|}
\hline \multicolumn{7}{|c|}{ Group 2} \\
\hline & \multicolumn{6}{|c|}{ Game } \\
\hline II) & 1 & 2 & 3 & 4 & 5 & \\
\hline 1 & $x$ & & $x$ & & $x$ & \\
\hline 2 & $x$ & & $x$ & $x$ & & \\
\hline 3 & $\bar{x}$ & & & & 0 & \\
\hline 4 & $x$ & $\bar{x}$ & 9 & 0 & 0 & \\
\hline 5 & $x$ & $\bar{x}$ & $\bar{x}$ & $x$ & $\bar{x}$ & \\
\hline 6 & $x$ & $\bar{x}$ & & $x$ & & \\
\hline 7 & $x$ & $\bar{x}$ & 0 & 0 & 0 & \\
\hline 8 & $x$ & $\bar{x}$ & 0 & 0 & & \\
\hline 9 & $x$ & 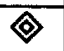 & $x$ & $\Leftrightarrow$ & & \\
\hline 10 & $x$ & & $x$ & $x$ & $x$ & \\
\hline 11 & & 可 & & Q & & \\
\hline 12 & $x$ & 0 & 0 & 0 & 0 & \\
\hline 13 & 0 & 0 & 0 & 0 & 0 & \\
\hline 14 & $x$ & $\bar{x}$ & $x$ & $x$ & 0 & \\
\hline 15 & & $\bar{x}$ & $\bar{x}$ & $\bar{x}$ & $x$ & \\
\hline 16 & $x$ & $x$ & $x$ & & 0 & \\
\hline 17 & & & & $x$ & & \\
\hline 18 & $x$ & $\bar{x}$ & $x$ & & 0 & \\
\hline
\end{tabular}

Index

$X$ - indistinguishable from a random sequence

\begin{tabular}{|c|c|c|c|}
\hline No. of times observed & $\mathrm{j}=1$ & $\mathrm{j}=2$ & $\mathrm{j}=3$ \\
\hline 16 & $\bullet$ & $\bullet$ & $\mathbf{\square}$ \\
\hline 15 & $\mathbf{0}$ & $\diamond$ & $\mathbf{D}$ \\
\hline 14 & $\odot$ & $\diamond$ & $\mathbf{D}$ \\
\hline
\end{tabular}


Table 4

Means and Standard Deviations of Observed Number of Entries and Minimum Switch Deviation from Pure equilibrium

\begin{tabular}{|c|c|c|c|c|c|c|c|c|c|}
\hline \multirow[b]{2}{*}{ Game } & & \multicolumn{2}{|c|}{$\mathrm{j}=1$} & \multicolumn{2}{|c|}{$\mathrm{j}=2$} & \multicolumn{2}{|c|}{$j=3$} & \multicolumn{2}{|c|}{$\operatorname{MinS}$} \\
\hline & & Mean & $\mathrm{SD}$ & Mean & $\mathrm{SD}$ & Mean & SD & Mean & $\mathrm{SD}$ \\
\hline \multirow[t]{4}{*}{1} & Group 1 & 7.06 & 1.57 & 6.00 & 1.79 & 4.94 & 1.34 & 1.81 & 0.90 \\
\hline & Group 2 & 7.31 & 1.25 & 6.19 & 2.01 & 4.50 & 1.79 & 1.94 & 1.29 \\
\hline & Mixed Eq. & 7.25 & 2.08 & 5.99 & 2.00 & 4.75 & 1.87 & 2.35 & 1.27 \\
\hline & Pure Eq. & 7 & & 6 & & 5 & & & \\
\hline \multirow[t]{4}{*}{2} & Group 1 & 9.19 & 2.37 & 5.69 & 2.63 & 3.12 & 1.20 & 2.88 & 1.19 \\
\hline & Group 2 & 8.56 & 1.09 & 6.25 & 1.73 & 3.19 & 1.05 & 1.50 & 1.15 \\
\hline & Mixed Eq. & 8.46 & 2.12 & 7.20 & 2.08 & 2.34 & 1.43 & 2.31 & 1.28 \\
\hline & Pure Eq. & 8 & & 7 & & 3 & & & \\
\hline \multirow[t]{4}{*}{3} & Group 1 & 8.81 & 1.52 & 3.81 & 1.52 & 5.28 & 2.06 & 2.31 & 1.41 \\
\hline & Group 2 & 9.19 & 1.76 & 4.94 & 1.77 & 3.88 & 1.71 & 2.13 & 0.81 \\
\hline & Mixed Eq. & 9.74 & 2.11 & 4.73 & 1.87 & 3.53 & 1.68 & 2.32 & 1.26 \\
\hline & Pure Eq. & 9 & & 5 & & 4 & & & \\
\hline \multirow[t]{4}{*}{4} & Group 1 & 11.19 & 2.04 & 5.75 & 2.05 & 1.06 & 0.57 & 2.06 & 1.33 \\
\hline & Group 2 & 10.75 & 2.05 & 6.06 & 2.29 & 1.19 & 0.54 & 1.94 & 1.48 \\
\hline & Mixed Eq. & 10.73 & 2.08 & 7.00 & 2.07 & 0.27 & 0.52 & 2.08 & 1.27 \\
\hline & Pure Eq. & 10 & & 7 & & 1 & & & \\
\hline \multirow[t]{4}{*}{5} & Group 1 & 12.38 & 2.42 & 3.25 & 2.02 & 2.38 & 1.36 & 2.50 & 1.11 \\
\hline & Group 2 & 11.75 & 1.81 & 3.75 & 1.73 & 2.50 & 1.55 & 2.00 & 0.97 \\
\hline & Mixed Eq. & 13.37 & 1.85 & 3.44 & 1.67 & 1.19 & 1.05 & 2.19 & 1.19 \\
\hline & Pure Eq. & 12 & & 4 & & 2 & & & \\
\hline \multirow[t]{4}{*}{6} & Group 1 & 15.56 & 0.81 & 1.38 & 0.81 & 1.06 & 0.25 & 0.88 & 1.33 \\
\hline & Group 2 & 15.12 & 0.81 & 1.87 & 0.81 & 1.00 & 0.37 & 0.56 & 0.63 \\
\hline & Mixed Eq. & 16.70 & 1.10 & 1.06 & 1.00 & 0.23 & 0.48 & 1.88 & 0.84 \\
\hline & Pure Eq. & 15 & & 2 & & 1 & & & \\
\hline
\end{tabular}


Table 5A

Frequency of decisions on time $t+1$ - Group 1

\begin{tabular}{|c|c|c|c|c|c|c|c|c|c|c|c|c|c|}
\hline \multirow[b]{3}{*}{ ID } & \multirow{2}{*}{\multicolumn{3}{|c|}{$\frac{\text { Not Rewarded }}{n_{t}>m_{t}}$}} & \multicolumn{7}{|c|}{ Rewarded } & & & \\
\hline & & & & \multicolumn{2}{|c|}{$\mathrm{n}_{\mathrm{t}}>\mathrm{m}_{\mathrm{t}}$} & \multicolumn{3}{|c|}{$n_{t}=m_{t}$} & \multicolumn{2}{|c|}{$\mathrm{n}_{\mathrm{t}}<\mathrm{m}_{\mathrm{t}}$} & \multicolumn{3}{|c|}{ Switch } \\
\hline & $=1$ & $\neq^{2}$ & & $=$ & $\neq$ & & $=$ & $\neq$ & $=$ & $\neq$ & $B^{3}$ & $\nabla^{4}$ & \\
\hline 1 & 0 & 8 & $\mathbf{a}$ & 17 & 23 & & 7 & 12 & 9 & 14 & 28 & 14 & $\bullet$ \\
\hline 2 & 10 & 0 & & 33 & 3 & & 16 & 3 & 21 & 4 & 6 & 4 & \\
\hline 3 & 6 & 4 & $\mathbf{0}$ & 42 & 4 & - & 15 & 0 & 19 & 0 & 4 & 1 & $\bullet$ \\
\hline 4 & 7 & 4 & & 29 & 15 & & 9 & 4 & 8 & 14 & 20 & 11 & $\bullet$ \\
\hline 5 & 7 & 11 & $\boldsymbol{\square}$ & 19 & 13 & & 13 & 2 & 13 & 12 & 9 & 23 & $\diamond$ \\
\hline 6 & 3 & 8 & & 24 & 23 & & 7 & 4 & 8 & 13 & 21 & 16 & \\
\hline 7 & 5 & 0 & & 39 & 3 & & 15 & 1 & 23 & 4 & 5 & 3 & \\
\hline 8 & 3 & 2 & & 24 & 24 & & 8 & 7 & 15 & 7 & 18 & 13 & \\
\hline 9 & 7 & 10 & & 12 & 22 & & 6 & 10 & 8 & 15 & 24 & 23 & \\
\hline 10 & 3 & 6 & & 18 & 18 & & 7 & 7 & 20 & 11 & 14 & 20 & \\
\hline 11 & 9 & 4 & & 23 & 16 & & 10 & 3 & 15 & 10 & 12 & 11 & \\
\hline 12 & 3 & 6 & $\mathbf{0}$ & 15 & 15 & - & 33 & 6 & 10 & 2 & 12 & 9 & \\
\hline 13 & 6 & 5 & & 36 & 10 & & 11 & 5 & 11 & 6 & 15 & 5 & $\bullet$ \\
\hline 14 & 4 & 4 & $\boldsymbol{a}$ & 35 & 6 & & 12 & 5 & 17 & 7 & 6 & 10 & \\
\hline 15 & 6 & 6 & & 20 & 10 & & 8 & 4 & 28 & 8 & 12 & 9 & \\
\hline 16 & 1 & 8 & $\mathbf{a}$ & 19 & 24 & & 7 & 11 & 10 & 10 & 23 & 17 & \\
\hline 17 & 3 & 6 & $\boldsymbol{\square}$ & 39 & 4 & - & 16 & 1 & 20 & 1 & 5 & 2 & \\
\hline 18 & 7 & 6 & & 17 & 17 & & 8 & 4 & 18 & 13 & 16 & 17 & \\
\hline ALL & 90 & 98 & $\boldsymbol{\square}$ & 461 & 250 & 0 & 208 & 89 & 273 & 151 & 250 & 208 & $\bullet$ \\
\hline
\end{tabular}

\begin{tabular}{|c|c|}
\hline $\begin{array}{l}1 \text { - stay } \\
2 \text { - Switch }\end{array}$ & $\begin{array}{l}\text { - The hypothesis that given a switch-out } \\
\text { from location a }\left(j_{t}=a\right) \text {, if }\left(n_{b(t)} \leq m_{b} \text { and } n_{c(t)}\right. \\
\left.>m_{c}\right) \text { or }\left(n_{b(t)}<m_{b} \text { and } n_{c(t)}=m_{c}\right) \text { then } P\left(j_{t+1}\right. \\
=b)>P\left(j_{t+1}=c\right) \text { is supported }(0.05) \text {. }\end{array}$ \\
\hline $\begin{array}{l}\text { - proportion of switching after no reward } \\
\text { is significantly higher than after reward } \\
(0.1) \text {. }\end{array}$ & $\begin{array}{l}\text { - The Hypothesis that } P\left(\mathrm{j}_{\mathrm{t}} \neq \mathrm{j}_{\mathrm{t}+1} \mid \mathrm{n}_{\mathrm{j}}>\mathrm{m}_{\mathrm{j}}\right) \\
>\mathrm{P}\left(\mathrm{j}_{\mathrm{t}} \neq \mathrm{j}_{\mathrm{t}+1} \mid \mathrm{n}_{\mathrm{j}} \leq \mathrm{m}_{\mathrm{j}}\right) \text { is supported }(0.05)\end{array}$ \\
\hline
\end{tabular}


Table 5B

Frequency of decisions on time $t+1-$ Group 2

\begin{tabular}{|c|c|c|c|c|c|c|c|c|c|c|c|c|c|}
\hline \multirow[b]{3}{*}{ ID } & \multirow{2}{*}{\multicolumn{3}{|c|}{$\frac{\text { Not Rewarded }}{n>m}$}} & \multicolumn{7}{|c|}{ Rewarded } & & & \\
\hline & & & & \multicolumn{2}{|c|}{$\mathrm{n}>\mathrm{m}$} & & \multicolumn{2}{|c|}{$\mathrm{n}=\mathrm{m}$} & \multicolumn{2}{|c|}{$\mathrm{n}<\mathrm{m}$} & \multicolumn{3}{|c|}{ Switch } \\
\hline & $=1$ & $\neq^{2}$ & & $=$ & $\neq$ & & $=$ & $\neq$ & $=$ & $\neq$ & $\beta^{3}$ & $\vartheta^{4}$ & \\
\hline 1 & 9 & 11 & $\square$ & 12 & 16 & 0 & 22 & 3 & 12 & 5 & 21 & 10 & $\bullet$ \\
\hline 2 & 1 & 6 & $\mathbf{0}$ & 19 & 19 & $\bullet$ & 16 & 5 & 18 & 6 & 18 & 8 & $\bullet$ \\
\hline 3 & 5 & 1 & & 24 & 15 & - & 20 & 5 & 16 & 4 & 9 & 10 & \\
\hline 4 & 5 & 2 & & 28 & 4 & & 21 & 4 & 22 & 4 & 4 & 5 & \\
\hline 5 & 1 & 5 & $\boldsymbol{\square}$ & 19 & 16 & & 15 & 11 & 15 & 8 & 20 & 10 & $\bullet$ \\
\hline 6 & 4 & 4 & & 17 & 22 & - & 19 & 9 & 10 & 5 & 16 & 14 & \\
\hline 7 & 5 & 4 & $\mathbf{a}$ & 28 & 8 & & 21 & 3 & 18 & 3 & 6 & 6 & \\
\hline 8 & 5 & 5 & $\mathbf{D}$ & 30 & 7 & 0 & 24 & 0 & 18 & 1 & 5 & 4 & \\
\hline 9 & 3 & 6 & $\boldsymbol{0}$ & 19 & 8 & - & 15 & 8 & 28 & 3 & 13 & 4 & $\bullet$ \\
\hline 10 & 2 & 8 & & 11 & 17 & & 10 & 16 & 14 & 12 & 24 & 18 & \\
\hline 11 & 7 & 5 & & 13 & 11 & $\bullet$ & 37 & 3 & 9 & 5 & 8 & 10 & \\
\hline 12 & 3 & 2 & $\boldsymbol{\square}$ & 33 & 3 & - & 26 & 1 & 22 & 0 & 3 & 3 & \\
\hline 13 & 5 & 1 & $\boldsymbol{\square}$ & 34 & 1 & & 26 & 0 & 23 & 0 & 2 & 0 & $\bullet$ \\
\hline 14 & 4 & 2 & & 25 & 12 & $\bullet$ & 23 & 4 & 16 & 4 & 11 & 8 & \\
\hline 15 & 3 & 8 & & 7 & 21 & $\bullet$ & 16 & 13 & 7 & 15 & 26 & 23 & \\
\hline 16 & 3 & 5 & & 16 & 15 & & 16 & 9 & 16 & 10 & 21 & 10 & $\bullet$ \\
\hline 17 & 2 & 2 & & 22 & 19 & & 13 & 12 & 8 & 12 & 25 & 11 & $\bullet$ \\
\hline 18 & 5 & 3 & & 27 & 7 & & 21 & 8 & 11 & 8 & 10 & 9 & \\
\hline ALL & 72 & 80 & 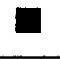 & 384 & 221 & - & 361 & 114 & 283 & 105 & 242 & 163 & $\bullet$ \\
\hline
\end{tabular}


Table 6

Cumulative probability distributions that a random sequence containing $\mathrm{n} 1$ elements of type 1 , $\mathrm{n} 2$ of type 2 and $\mathrm{n} 3$ of type 3 will contain $\mathrm{R}$ number of runs

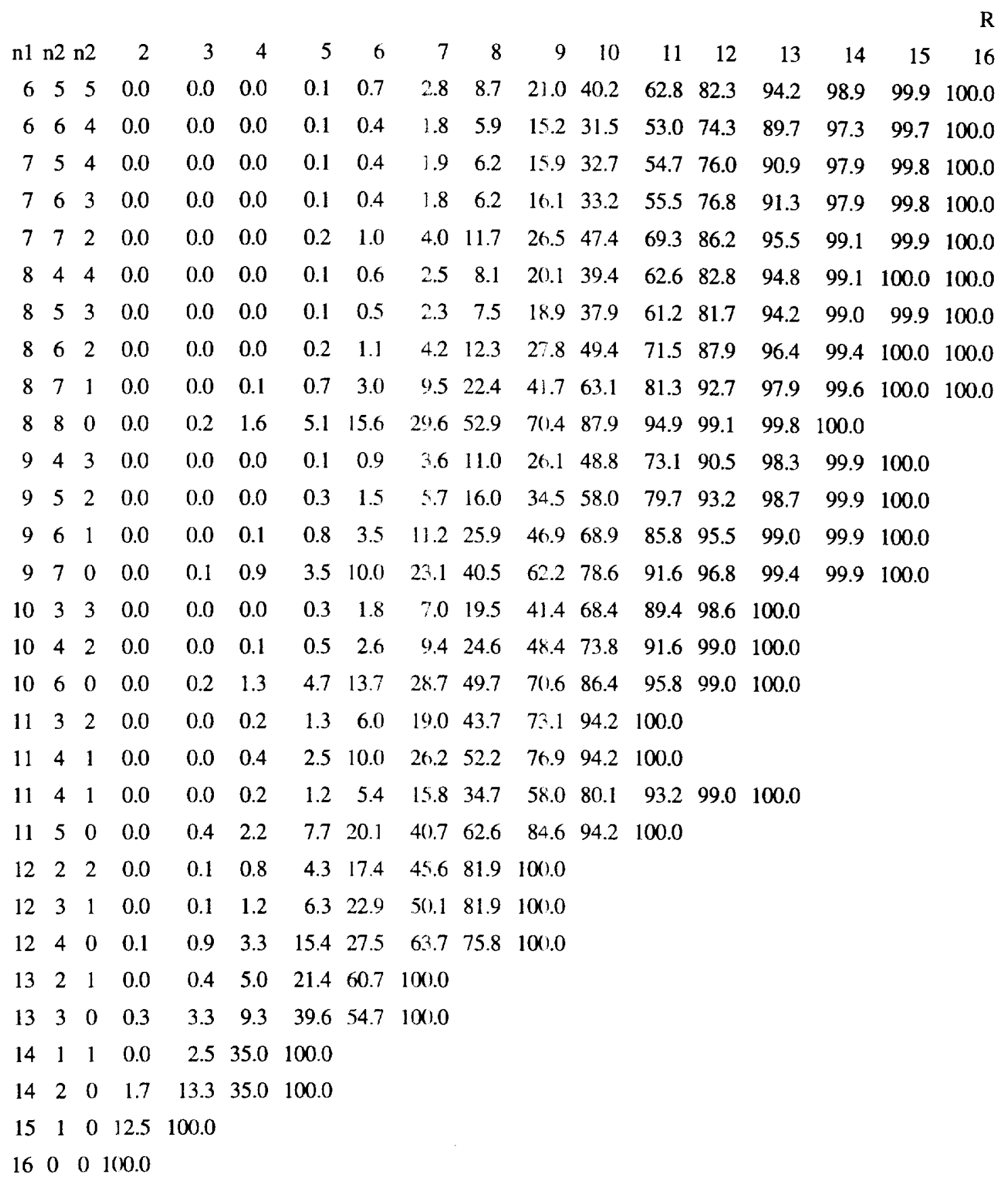


Table 7

Frequency of reward / no-reward by location for a group level simulated subjects

\begin{tabular}{|c|c|c|c|c|}
\hline & $\%$ & $\mathrm{j}=1$ & $\mathrm{j}=2$ & $\mathrm{j}=3$ \\
\hline Rewarded & row & 0.610 & 0.242 & 0.149 \\
$(88.4 \%)$ & column & 0.921 & 0.852 & 0.801 \\
& cell & 0.539 & 0.214 & 0.131 \\
\hline Not Rewarded & row & 0.399 & 0.319 & 0.282 \\
$(11.6 \%)$ & column & 0.079 & 0.148 & 0.199 \\
& cell & 0.046 & 0.037 & 0.033 \\
\hline
\end{tabular}


Table 8

Proportions of games with over- and under-subscribers by location for the simulated data

\begin{tabular}{cccc}
\hline$n_{j}$ vs. $m_{j}$ & $j=1$ & $j=2$ & $j=3$ \\
\hline$<$ & 0.267 & 0.656 & 0.189 \\
$=$ & 0.156 & 0.144 & 0.489 \\
$>$ & 0.578 & 0.200 & 0.322 \\
\hline
\end{tabular}


Appendix 1

Instructions to Subjects

\section{Greetings!}

You are about to participate in a decision making study. At the end of the session you will be paid according to your performance. A research foundation has contributed the funds to support this research.

Please read the instructions very carefully.

You are going to participate in many rounds of basically the same game. The game is very simple. If you make good decisions, you increase your chances of earning a considerable amount of money.

\section{The game}

The game is played by a group of 18 players (all those who are currently present at the PC Lab). You will repeatedly play the game (in rounds) with the same group of 18 players.

On each round, three lotteries will be conducted (called the YELLOW, BLUE and RED lotteries). You can participate in one and only one of these lotteries. You will be asked to choose participating in one of these lotteries without knowing the lotteries the other players in your group have selected.

At the beginning of each round, the information about the three lotteries will be presented in the following way:

\section{Example}

Number of players in the group: 18 (you are one of them)

\begin{tabular}{|l|c|c|c|}
\hline Prize & 10 & 10 & \\
\hline \# prizes offered & 2 & 4 & 12 \\
\hline \# chosen & & & \\
\hline
\end{tabular}

In this round:

$\begin{array}{lllll}\text { The YELLOW } & \text { lottery offers } & 2 & \text { prize of } & \$ 10 \text {. } \\ \text { The RED } & \text { lottery offers } & 4 & \text { prize of } & \$ 10 \text {. } \\ \text { The BLUE } & \text { lottery offers } & 12 & \text { prize of } & \$ 10 .\end{array}$

Your task is to choose participating in one of these lotteries.

Because the number of prizes offered in each of the three lotteries may vary from round to round, you should pay close attention to them.

After all the members in your group choose which lottery to play, the computer will display the number of players who chose each of the three lotteries in the following manner:

\footnotetext{
${ }^{1}$ Colors were presented by the actual color on the screen
} 
Number of players in the group: 18 (you are one of them)

\begin{tabular}{|l|c|c|c|}
\hline Prize & 10 & 10 & \\
\hline \# prizes offered & 2 & 4 & 12 \\
\hline \# chosen & 6 & 8 & 4 \\
\hline
\end{tabular}

For example, in this round, 6 players chose to play the YELLOW lottery, 8 to play the RED lottery, and 4 to play the BLUE lottery (note that $6+8+4=18$ ).

\section{How winners are chosen in each lottery?}

If the number of players who choose to play in a given lottery is equal to or less than the number of prizes offered in this lottery then each one of them will win the prize.

If, however, the number of players who choose to play in a given lottery is more than the number of available prizes offered in this lottery then the computer will randomly select as many winners out of them as there are prizes this lottery.

For example, if 6 players chose the YELLOW lottery, 8 chose the RED lottery, and 4 chose the BLUE lottery, then the 4 players who had chosen the BLUE lottery wins $\$ 10$ each because the number of players who chose the BLUE lottery (4) is less than the number of available prizes in this lottery (12).

Two of the 6 players who chose the YELLOW lottery will be randomly selected to win $\$ 10$, and four of the 8 players who chose the RED lottery will be randomly selected to win $\$ 10$.

Each of the 6 players who choose the YELLOW lottery is equally likely to be selected as one of the winners of the $\$ 10$. Similarly, each of the 8 players who choose the RED lottery is equally likely to be selected as one of the winners of the $\$ 10$.

Naturally, if no one choose any particular lottery, the prizes of this lottery are not awarded.

On each round, if you are not selected to win a prize in the lottery you chose, your payoff for this round is zero.

\section{Summary}

If the number of players who choose to play in a given lottery is equal to or less than the number of prizes offered in this lottery then each one of these players will win the offered prize in this lottery.

If, however, the number of players who choose to play in a given lottery is more than the number of available prizes offered in this lottery then the more players choose the same lottery the smaller the chances for each one of them to win that lottery prize.

We shall now test your understanding of the game. If your answers are incorrect, the computer will show you the correct answers and explain them. 


\section{How do we pay you for your participation?}

Your payoff for the session will equal your cumulative payoffs in all rounds.

The highest possible take home pay is $\$ 222$. This can happen if you always win the lottery on all rounds.

The lowest possible take home pay is $\$ 30$. This can happen if you never win any prize in all rounds and you only get paid the show up fee.

The University regulation requires that all participants read and accept the conditions of the study.

For the consent form please press the consent form button.

Deleted

From now on you may not communicate with other participants or anyone else for that matter.

Please raise your hand to indicate to the monitor that you have finished reading the instructions. The Monitor will answer any questions you may have and will start the program for you. 
Appendix 2

Screen shots for the decision task

Selection was done by pressing on the color corresponding for the choice

\begin{tabular}{|c|c|c|c|c|}
\hline Screen 1 & & & & \\
\hline & Round: 1 & & & \\
\hline & Prize & & & 2 \\
\hline & No. Available & 7 & 6 & 6 \\
\hline & No. Chosen & & & \\
\hline & $\begin{array}{l}\text { Please choo } \\
\text { pressing on } t \\
\text { the lo }\end{array}$ & & lotte & \\
\hline
\end{tabular}

After the selection subjects were instructed to confirm or cancel their choice

\begin{tabular}{|c|c|c|c|c|}
\hline \multicolumn{5}{|l|}{ Screen 2} \\
\hline & Prize & & & 2 \\
\hline & No. Available & 7 & 6 & 6 \\
\hline & No. Chosen & & & \\
\hline \multicolumn{5}{|c|}{$\begin{array}{l}\text { You have Chosen to participate in the } \\
\text { RED lottery, please confirm or cancel } \\
\text { your choice }\end{array}$} \\
\hline
\end{tabular}


After confirmed choice, subjects were instructed to wait for the decision of all other players

\begin{tabular}{l} 
Screen 3 \\
$\qquad$\begin{tabular}{|c|c|c|c|}
\hline Round: 1 & & 2 \\
\hline Po. Avaize & & 6 & 6 \\
\hline No. Chosen & & & \\
\hline \\
You have Chosen to participate in the \\
RED lottery, please wait for the outcome \\
of this round....
\end{tabular} \\
\hline
\end{tabular}

After the outcome is presented, if $n_{j}>m_{j}$ for the selected location, subjects were instructed to wait for the random selection of winners

\begin{tabular}{|c|c|c|c|c|}
\hline \multirow[t]{5}{*}{ Screen 4} & \multicolumn{3}{|l|}{ Round: 1} & \\
\hline & Prize & & & 2 \\
\hline & No. Available & 7 & 6 & 6 \\
\hline & No. Chosen & 4 & 10 & 4 \\
\hline & \multicolumn{4}{|c|}{$\begin{array}{l}\text { You have Chosen to participate in the } \\
\text { RED lottery. Please wait for the random } \\
\text { selection of } 6 \text { players out of the } 10 \text { who } \\
\text { have chosen to participate in the RED } \\
\text { lottery..... }\end{array}$} \\
\hline
\end{tabular}


If the subject was randomly sleeted to win the prize

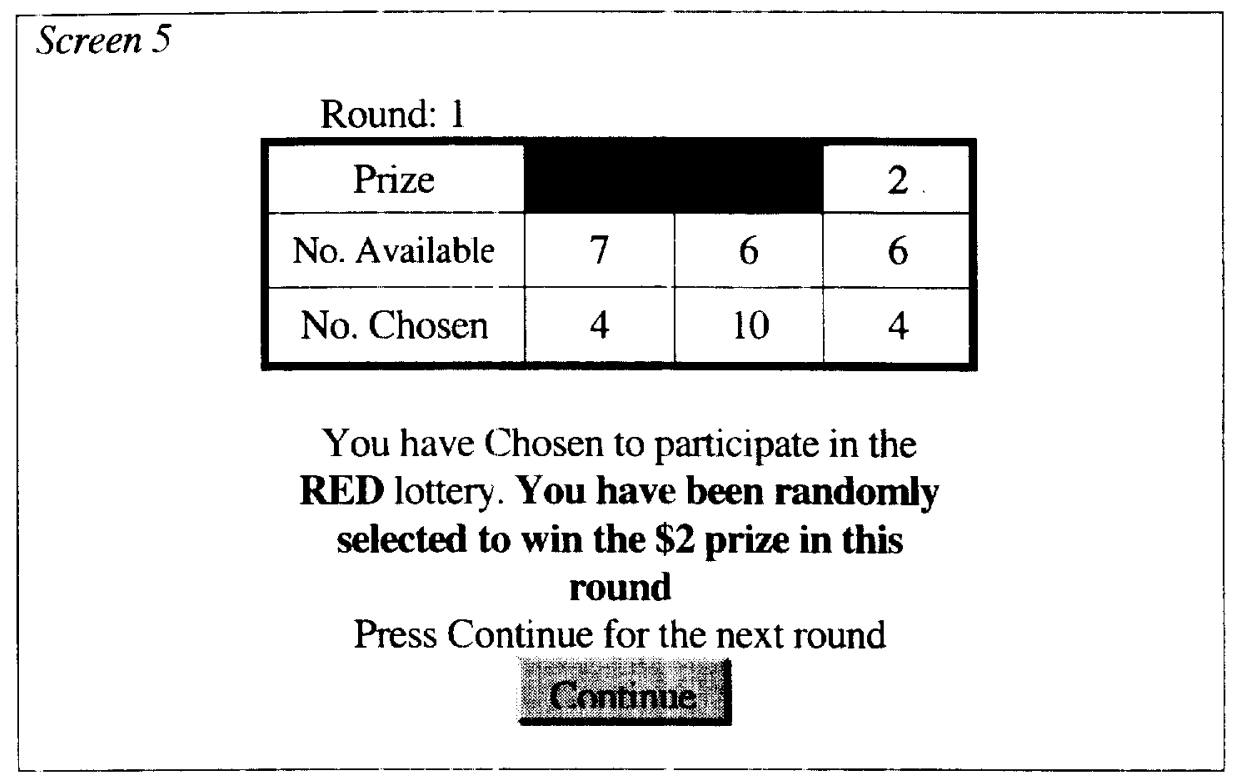

If the subject was not randomly sleeted to win the prize

\begin{tabular}{|c|c|c|c|c|}
\hline Screen 6 & Round: 1 & & & \\
\hline & Prize & & & 2 \\
\hline & No. Available & 7 & 6 & 6 \\
\hline & No. Chosen & 4 & 10 & 4 \\
\hline & $\begin{array}{l}\text { You have } \\
\text { RED lotte } \\
\text { randomly sel } \\
\text { Press Cor }\end{array}$ & is $\mathrm{r}$ & $\begin{array}{l}\text { icip } \\
\text { NO } \\
\text { the }\end{array}$ & $\begin{array}{l}\text { the } \\
\text { en } \\
\text { ize in } \\
\text { d }\end{array}$ \\
\hline
\end{tabular}


Please forward your requests for working papers to the following address:

\section{Executive Officer}

Department of Marketing

School of Business and Management

Hong Kong University of Science \& Technology

Clear Water Bay

Kowloon, Hong Kong

www: http://www.bm.ust.hk/ mark/

Enquiries: $\quad$ Tel (852) $23587700 \quad$ Fax (852) 23582429 